\title{
Factors controlling stable isotopes variability in precipitation in Syria: Statistical analysis approach
}

\author{
ZUHAIR KATTAN \\ Department of Geology, Atomic Energy Commission of Syria (AECS), P.O. Box 6091, Damascus, \\ Syrian Arab Republic. \\ e-mail: cscientific5@aec.org.sy
}

MS received 19 June 2018; revised 7 November 2018; accepted 10 November 2018; published online 4 June 2019

The major characteristics of the stable isotopes $\left({ }^{18} \mathrm{O}\right.$ and $\left.{ }^{2} \mathrm{H}\right)$ and deuterium excess $(d$-excess or $d)$ of rainfall samples collected from 16 stations during two periods (1989-1993 and 2003-2006) were statistically analysed to understand the factors controlling the temporal and spatial isotope variability in precipitation $(P)$ in Syria. Rainfall waters at the mountainous regions are remarkably the most depleted in heavy stable isotopes, with also high $d$-excess values $(d>20 \%$ ). The enriched rainfall waters (lower $d$-excess values), mostly referring to coastal and some inland areas, are subject to the evaporation of falling raindrops. Rainfalls at the southern stations have impressively the highest $d$-excess values $(d>22 \%)$, likely because of intensive interactions with the Mediterranean Sea (MS) moistures. The temperature $(T)$ effect, shown by an average $\delta^{18} \mathrm{O}$ gradient of $\approx 0.34 \pm 0.03 \% /{ }^{\circ} \mathrm{C}$, is very close to the Global Network for Isotopes in Precipitation value $\left(0.3 \% /{ }^{\circ} \mathrm{C}\right)$. The altitude effect, represented by a $\delta^{18} \mathrm{O}$ gradient of $-0.18 \pm 0.03 \% / 100 \mathrm{~m}$, fits well with the range given for most Mediterranean countries. Relative humidity $(\mathrm{RH})$ and $P$-amount effects are characterised by an isotopic depletion, with a notable rise in the $d$-excess value with $P$ and RH increases. The seasonal effect is shown by depleted $\delta^{18} \mathrm{O}$ and $\delta^{2} \mathrm{H}$ values during December-February and enriched $\delta^{18} \mathrm{O}$ and $\delta^{2} \mathrm{H}$ values at the end of April, with frequently low $d$-excess values $(<8 \%)$. $T$ parameter seems to be the major factor that strongly controls the variability of the stable isotope compositions of $P$ in Syria. The moisture from the MS and secondary evaporation conjunctly play additional roles, but of less importance than the $T$ effect.

Keywords. Hydrology; environmental isotopes; stable isotopes; precipitation; rainfall; Syria.

\section{Introduction}

Meteoric water is the main source of water in almost all hydrological systems on the Earth. Hence, knowledge of the distribution patterns of the stable isotopes $\left({ }^{2} \mathrm{H}\right.$ and $\left.{ }^{18} \mathrm{O}\right)$ in rainfall waters can provide useful information, not only on a comprehensive understanding of the water cycle (Gat 1980, 1996; Mook 2001; IAEA 2005a), but also on the appropriate use of such isotopes in diverse hydrological, hydrogeological and geochemical studies (Fritz and Fontes 1980; IAEA 1995, 1998; Clark and Fritz 1997; Ingraham 1998; Criss 1999; Hoefs 2009).

The importance of ${ }^{2} \mathrm{H}$ and ${ }^{18} \mathrm{O}$, as the best natural tracers in most hydrological and meteorological studies, is basically because of their physical properties, likely as both atoms enter the formulation of the water molecule. These isotopes, commonly known as the conservative fingerprints 
of water, can reflect all modification processes occurring in most water systems (Gat 1980; Mook 2001). Hence, they are largely and successfully used for a better understanding of the temporal and spatial isotope variability trends in precipitation $(P)$ on local and large scales (Rozanski et al. 1993; Bowen and Wilkinson 2002; Bowen and Revenaugh 2003; Dutton et al. 2005; Sturm et al. 2005). Also, they are effectively applied in studying the circulation of water vapour in the atmosphere and ocean waters (Zahn et al. 1998; Gat et al. 2003; Aggarwal et al. 2004; Schulz and Zabel 2006; Liu et al. 2010; Tanhua et al. 2013). Information on their distribution in rainfall waters at different elevations is also useful for delineating the altitude of groundwater recharge zones (Mathieu and Bariac 1996; Kattan 1997a, 2006; Gonfiantini et al. 2001; Harrington et al. 2002; Kumar et al. 2010; Windhorst et al. 2013).

Based on the strong dependence between temperature $(T)$ and stable isotope ratios found in the earth archives, these isotopes are widely used in studying the global climate changes and past continental environments (IAEA 1983; Johnsen et al. 1989; Koch 1998; Aizen et al. 2005). Due to the importance of such environmental tracers in the diverse hydrological domains, a worldwide isotope survey, focused on their distribution in $P$, was initiated in the early 1960s (IAEA-WMO 2006). The gathered data from this survey helped to define the main factors affecting the global isotope variability (Dansgaard 1964; Yurtsever and Gat 1981; Rozanski et al. 1993; Schotterer et al. 1996). Previous studies in a number of Mediterranean countries, where the stable isotope compositions of $P$ and water vapour were conjunctly analysed, show that their variations are mainly due to changes in the air $T$ value and origin of the humid air masses producing rains (IAEA 2005b).

These studies also show that the isotopic compositions of ${ }^{18} \mathrm{O}$ and ${ }^{2} \mathrm{H}$ in $P$ become more depleted at higher elevations, with a $\Delta \delta^{18} \mathrm{O} / \Delta T$ gradient ranging between $-0.1 \%$ and $-0.6 \%$ (IAEA 2005b), and that the $d$-excess value varies from $14 \%$ in the western Mediterranean basin to $\approx 22 \%$ in the eastern part, likely because of admixture between the Atlantic Ocean (AO) air masses $(d=10 \%)$ and moistures produced from the Mediterranean sea (MS).

Despite the largeness of the eastern Mediterranean region, the information on the isotopic composition of $P$ in this part, especially in Syria, is still rather limited. The knowledge on the behaviours of such isotopes in $P$ in this region is mostly due to the Bet-Dagan coastal station, as it is the unique station belonging to the Global Network for Isotopes in Precipitation (GNIP) network in this area (IAEA-WMO 2006). However, few previous studies were conducted in Syria (Kattan 1997b; Abou Zakhem and Hafez 2007; Al-Charideh and Abou Zakhem 2010) and some neighboring countries (Saad et al. 2005; Bajjali 2012), but the information gained from these studies was not sufficient, because all these studies were based on short monitoring periods (1-3 yrs). The attempt, which was made by Lykoudis and Argiriou (2007), to produce modelled isotopic grids of data sets of $P$ across the eastern Mediterranean region, led to unrealistic data sets. The accuracy of the obtained data was not enough to detect certain local effects. Hence, still there is a need for a comprehensive understanding of the real distribution patterns of such isotopes in $P$ across this region.

This work, which aims to provide a part of the results already obtained from the statistical analysis of ${ }^{18} \mathrm{O},{ }^{2} \mathrm{H}$ and the $d$-excess data of rainfall samples collected from 16 stations in Syria, has the following major objectives: (i) characterising the stable isotope compositions of $P$ at different geographical locations; (ii) defining the local meteoric water line (LMWL) in Syria; and (iii) defining the roles of major meteorological parameters $(T$, $P$-amount, relative humidity $(\mathrm{RH}))$, together with the effects of altitude $(H)$ and seasonality, that can conjunctly control the temporal and spatial isotope variability in $P$. Noting here that this work will be followed by another publication focusing on the spatial isotope variability across this country, specifically in defining the roles of the key geographic parameters (longitude east (LE), latitude north (LN) and inland distance from the coast (DFC)). Hence, both studies are certainly of utmost importance to properly apply these natural tracers in the diverse hydrological, hydrogeological and climate studies in the country.

\section{Study area}

Syria lies on the eastern coast of the MS, located between $35^{\circ} 30^{\prime}-42^{\circ} 20^{\prime} \mathrm{E}$ of longitude and $32^{\circ} 30^{\prime}-$ $37^{\circ} 20^{\prime} \mathrm{N}$ of latitude (figure 1 ). This country, which covers a total area of $185,180 \mathrm{~km}^{2}$, geographically comprises, from west to east, the following major units: (i) the coastal plain (width up to $50 \mathrm{~km}$ ) located in the west, bordering the MS; (ii) the 


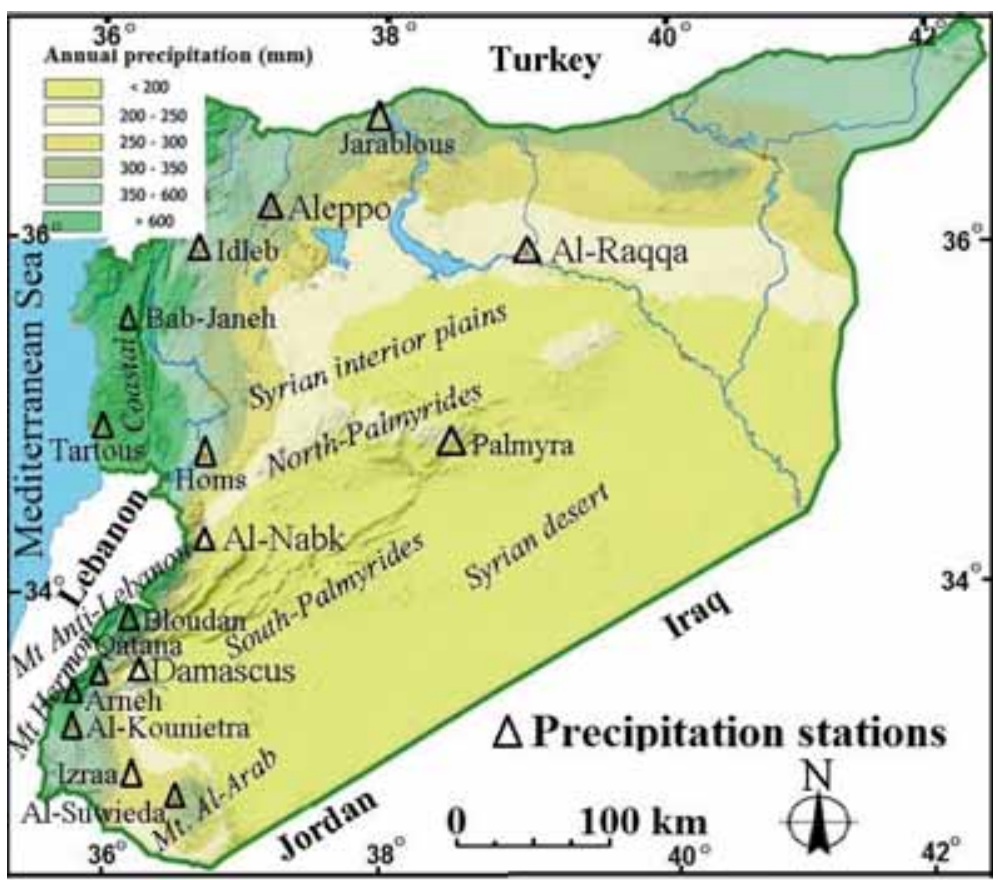

Figure 1. Location map of Syria showing the distribution of annual $P$ and locations of rainfall sampling.

coastal series of mountains (elevation up to 1575 $\mathrm{m}$ above sea level (a.s.l.)), extending in parallel to the MS; (iii) the Mt Hermon (2814 m), extending on the border between Syria and Lebanon; (iv) the Mt Al-Arab (1790 m), situated in southern Syria near the border with Jordan; (v) the interior hills and mountain series of Mt Anti-Lebanon (2466 m) and Palmyrides (1308 m), occupying the central part of the country; and (vi) the interior plains and desert region extending from the eastern mountainous ridges to the borders with Jordan and Iraq.

The climate in Syria is generally of a Mediterranean type, with mild wet winters and warm to hot and dry summers. Air $T$ value frequently falls in winter below $0^{\circ} \mathrm{C}$, but rarely below $-10^{\circ} \mathrm{C}$, and may rise in summer up to $48^{\circ} \mathrm{C}$. December and January are the coldest months, while July and August are the hottest. The daily difference between minimum and maximum $T$ values is rather high $\left(>23^{\circ} \mathrm{C}\right)$ in most parts of the country, especially in the desert regions, and often it is lower than $13^{\circ} \mathrm{C}$ in the coastal plain and mountainous regions (www.climate-data.org; www.climatemps. com).

The $\mathrm{RH}$ values are generally high in winter and low in summer, ranging in winter along the Syrian coast around $60-70 \%$, and around $60-80 \%$ in the interior areas. However, due to the sea effect, the $\mathrm{RH}$ values along the coastal plain are usually high
(70-80\%) in summer, while remarkably much lower $(20-50 \%)$ in the interior regions.

The rainy season in Syria extends between October and May, with a number of rainy (wet) days ranging between 35 and 92 days (climatedata.org). The position of the mountainous ranges is a decisive factor in the distribution of $P$ density. Hence, the heaviest rains $(P>1000 \mathrm{~mm} / \mathrm{a})$ coincide with the coastal mountains, where the air $T$ values are generally moderated all over the year, and the $\mathrm{RH}$ values are mostly high, even in summer. The reason that the $P$-amount is usually high in the coastal mountains is likely because of the path of most rainy depressions over the MS that are mostly accompanied by humid air masses. When these masses meet the mountains, they are forced to rise up, and thus to precipitate under the form of rain and snow. However, within the interior mountainous regions, where the altitudes are higher than $\approx 1000 \mathrm{~m}$ a.s.l., the $P$-amounts are also high in winter $(400-800 \mathrm{~mm})$, most probably because of the orographic rains occurring at these places. The regions with high altitudes (800-1500 $\mathrm{m}$ a.s.l.) are subjected to both rain and snow, while those of lower altitudes are usually subjected to rain, and rarely to snow, except the desert areas, where even sufficient rain seldom falls (figure 1). The lowest $P$ amounts $(<100 \mathrm{~mm})$ usually coincide with the desert regions. As it was found in most Mediterranean areas during the 20th century 
(Giorgi 2002), Syria is also subjected from time to time to dry seasons, rain shortages and negative $P$ trends.

\section{Origin and trajectory of air masses}

Syria, as most of the eastern Mediterranean countries, is usually subjected during winter to westerly and southwesterly winds, often accompanied by the humid air mass fronts, known as the North Atlantic Oscillation (NAO), while in summer it is completely isolated from the influence of the NAO masses (Hurrell et al. 2004). The prevailed winds in the eastern parts of the country in winter are mainly easterly, while in summer, the prevailing winds in both the northern and northeastern parts are northerly. Classification of the wind directions in the Damascus region during the entire study period (December 1989-May 2006) into the four geographic sectors (northeast $(\mathrm{NE})$, southeast (SE), southwest (SW) and northwest $(\mathrm{NW})$ ) reveals that $\approx 46 \%$ of prevailed winds were from the SW direction, while the remaining prevailed winds $(19.5 \%, 19 \%$ and $15.5 \%)$ were from the NW, NE and SE directions, respectively (www. weatheronline.co.uk).

Syria is also subjected during winter to cold rainy fronts coming from the Siberian system and the Northern Pole, while during spring and autumn periods, it may receive weak seasonal showers accompanied by tiny sand particles (Khamasin), mainly originating from North Africa, the Red Sea and the western parts of the Arabian Peninsula (Al-Momani et al. 1995). The southern parts of Syria may also receive during summer weak showers (monsoon) from the Indian Ocean (Gat et al. 2005).

As it was previously shown in several meteorological observations in many Mediterranean countries (IAEA 2005b) by using the National Oceanic and Atmospheric Administration (NOAA) Hysplit Model (https://ready.arl.noaa.gov/HYSPLIT. php), it is possible to distinguish during the rainy period between seven major backward trajectory tracks for the origin of air masses producing rains all over the country (figure 2):

1. from the Siberian Plateau, via Turkey, the Caspian Sea or Iran (no contact with the MS);

2. from the Northern Pole, via Eastern Europe, the Black Sea and Turkey (no contact with the MS);

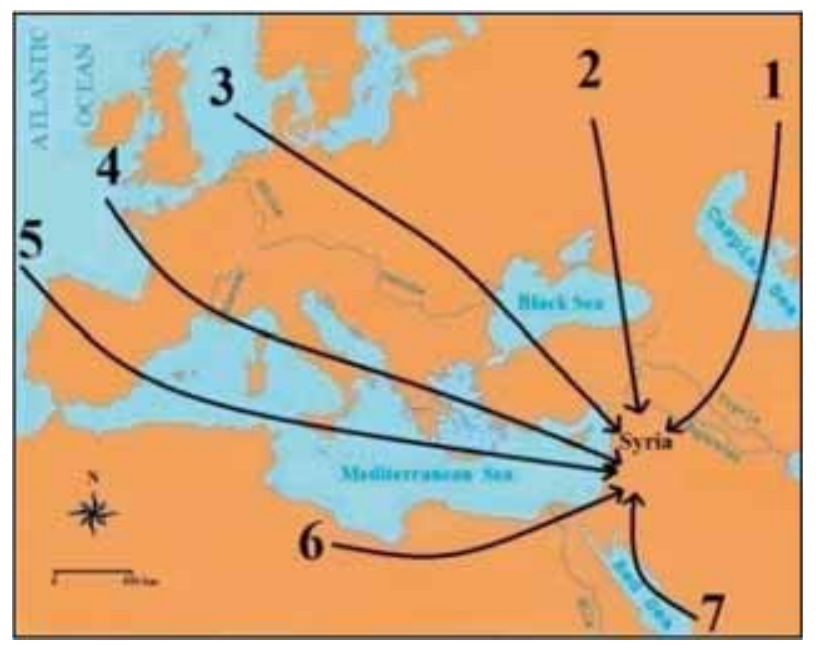

Figure 2. Origin and backward trajectory tracks of most possible air masses producing rains in Syria.

3. from the Atlantic Ocean (AO), via Eastern Europe, the Black Sea and Turkey (no contact with the MS);

4. from the AO, via Western Europe and the Greek islands (small contact with the northern MS);

5. from the AO, via the Iberian Peninsula, Cecile and the Greek islands (long contact with the central MS);

6. from Northern Africa, via Libya and the Sinai Peninsula in Egypt (small contact with the southern MS);

7. from the Red Sea, via the Arabian Peninsula, the Sinai Peninsula and Jordan (no contact with the MS).

Figure 3 shows four different cases, selected from the simulated HYSPLIT 72-hr backward trajectory tracks for the air masses reaching Damascus area at a height of $675 \mathrm{~m}$ a.s.l. during different dates within the period of this study.

\section{Sampling and analytical methods}

About 290 rainfall samples were collected from a network covering 16 stations distributed in the following areas: Aleppo, Al-Kounietra, Al-Nabk, Al-Raqqa, Al-Suwieda, Bab-Janeh, Bloudan, Damascus, Arneh, Homs, Idleb, Izraa, Jarablous, Palmyra, Qatana and Tartous (figure 1). Table 1 summarises the geographical coordinates of the rainfall sampling stations, along with a summary background of averaged values calculated for the major meteorological parameters (air $T, \mathrm{RH}$ and $P$-amount) at all stations during the sampling periods. The values of the related parameters were 

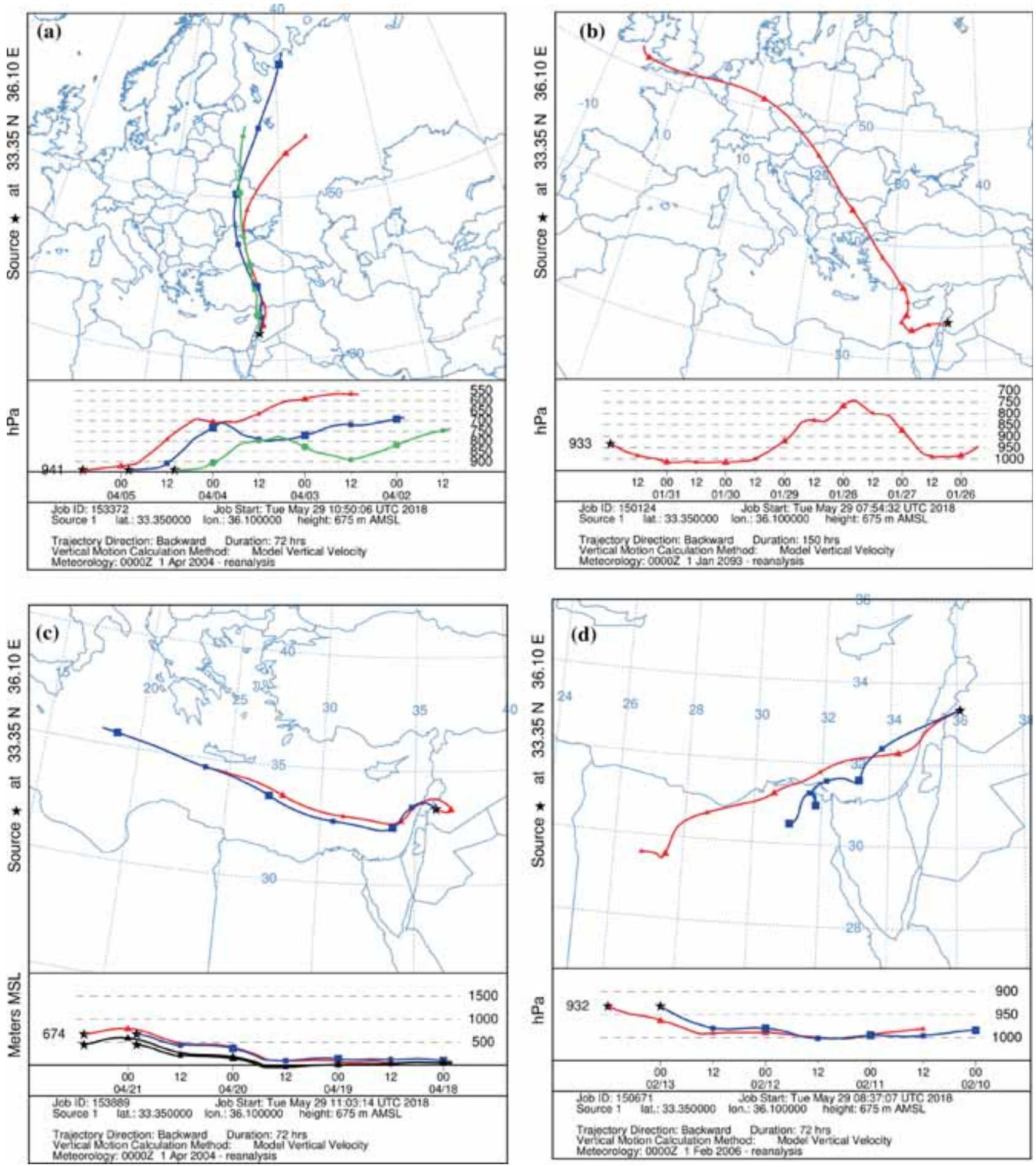

Figure 3. Simulated HYSPLIT 72-hr backward trajectory tracks of selected air masses reaching the Damascus area $(H=675$ m a.s.l.): (a) from the Northern Pole, via Eastern Europe and Turkey, on 5 April 2004; (b) from the AO, via Western and Eastern Europe, Turkey and the MS, on 31 January 1993; (c) from the central MS, via Lebanon, on 21 April 2004 and (d) from Northern Africa, via the MS and south Lebanon, on 13 February 2006.

measured daily by the local staff of the National Directorate of Meteorology.

Rainfall sampling was made on a monthly basis during two sampling periods (1989-1993 and 20032006). Table 2 illustrates the number of collected samples from each station, together with the date of the sampling period. The sampling from a number of stations during some months, mainly during the period 1994-2002, was not possible because of certain logistical and financial difficulties. Noting 
Table 1. Summary data showing the geographical coordinates (longitude east, LE; latitude north, $L N$; altitude, $H$; and distance from the coast, DFC) and averaged values of the main meteorological parameters (precipitation amount, $P$; surface air temperature, $T$ and relative air humidity, $R H$ ) for 16 sampling stations in Syria during the two sampling periods (1989-1993 and 2003-2006).

\begin{tabular}{|c|c|c|c|c|c|c|c|}
\hline Station & LE & $\mathrm{LN}$ & $\begin{array}{l}{ }^{*} H \\
(\mathrm{~m})\end{array}$ & $\begin{array}{l}\mathrm{DFC} \\
(\mathrm{km})\end{array}$ & $\begin{array}{c}P \\
(\mathrm{~mm})\end{array}$ & $\begin{array}{c}T \\
\left({ }^{\circ} \mathrm{C}\right)\end{array}$ & $\begin{array}{l}\mathrm{RH} \\
(\%)\end{array}$ \\
\hline Aleppo & 37.00 & 36.10 & 410 & 110 & $35.3 \pm 24.3$ & $7.9 \pm 5.6$ & $70.9 \pm 11.6$ \\
\hline Al-Kounietra & 35.88 & 33.18 & 930 & 60 & $89.0 \pm 72.2$ & $9.0 \pm 3.3$ & $73.9 \pm 12.4$ \\
\hline Al-Nabk & 36.75 & 34.05 & 1290 & 100 & $13.6 \pm 8.6$ & $10.2 \pm 6.2$ & $63.8 \pm 9.1$ \\
\hline Al-Raqqa & 39.08 & 35.95 & 250 & 290 & $27.2 \pm 18.5$ & $9.3 \pm 7.2$ & $66.6 \pm 13.0$ \\
\hline Al-Suwieda & 36.65 & 32.82 & 1020 & 140 & $68.9 \pm 51.0$ & $8.0 \pm 3.3$ & $70.3 \pm 10.5$ \\
\hline Bab-Janeh & 36.25 & 33.45 & 1050 & 30 & $92.8 \pm 77.8$ & $10.9 \pm 4.4$ & $66.2 \pm 6.7$ \\
\hline Bloudan & 36.14 & 33.75 & 1540 & 55 & $95.8 \pm 81.9$ & $7.8 \pm 6.1$ & $68.4 \pm 14.3$ \\
\hline Damascus & 36.10 & 33.35 & 675 & 80 & $31.1 \pm 21.9$ & $10.9 \pm 4.6$ & $59.9 \pm 15.5$ \\
\hline Arneh & 35.88 & 33.36 & 1430 & 50 & $147.5 \pm 127.6$ & $5.0 \pm 5.5$ & $78.8 \pm 10.1$ \\
\hline Homs & 36.68 & 34.75 & 490 & 70 & $66.9 \pm 45.9$ & $9.7 \pm 4.1$ & $70.5 \pm 11.7$ \\
\hline Idleb & 36.90 & 36.33 & 450 & 65 & $68.7 \pm 47.7$ & $11.1 \pm 4.6$ & $71.2 \pm 9.6$ \\
\hline Izraa & 36.22 & 32.85 & 580 & 105 & $54.6 \pm 53.1$ & $8.5 \pm 3.5$ & $73.8 \pm 8.9$ \\
\hline Jarablous & 38.03 & 36.82 & 350 & 160 & $42.9 \pm 26.4$ & $9.6 \pm 4.8$ & $68.8 \pm 10.0$ \\
\hline Palmyra & 38.25 & 34.58 & 400 & 210 & $14.7 \pm 9.4$ & $9.2 \pm 4.6$ & $60.6 \pm 12.0$ \\
\hline Qatana & 36.15 & 33.35 & 890 & 75 & $39.3 \pm 35.4$ & $10.8 \pm 4.3$ & $65.8 \pm 12.2$ \\
\hline Tartous & 35.88 & 34.90 & 5 & 0 & $122.2 \pm 85.8$ & $14.3 \pm 2.8$ & $65.4 \pm 5.0$ \\
\hline
\end{tabular}

${ }^{*} H$ : Altitude in $\mathrm{m}$ a.s.l.

here that all rainfall samples collected before 1994 were analysed in Amman/Jordan, through the regional project, entailed 'Isotope Hydrology in the Middle East (RER/8/002)', that was conducted in full cooperation with the International Atomic Energy Agency (IAEA). Later, by the beginning of 2003, as it was possible to conduct the isotopic analyses of water samples in Syria at the Geology Department of AECS, the second set of $P$ samples (2003-2006) was performed in this laboratory.

Rainfall waters were generally collected twice a day (morning and night) using plastic containers with effective catch-diameters $(30-80 \mathrm{~cm})$, depending on the $P$-amount at the considered station. The water collected daily was then transferred into a tightly stoppered container large enough to accommodate the monthly $P$-amount. A small amount of paraffin oil was added to each container in order to minimise the effect of evaporation, precisely for the first set of $P$ samples (1989-1993), for which the subsequent isotopic analyses were performed in Jordan. Later, precisely for the remaining set of rainfall samples, paraffin oil was not added, likely because it was possible to conduct these analyses in a short time in the Geology Department of AECS.

At the end of the rainy months, a small (50 $\mathrm{ml}$ ) rinsed bottle (glass or polyethylene) was filled for the determination of the stable isotopes $\left({ }^{18} \mathrm{O}\right.$ and ${ }^{2} \mathrm{H}$ ). Immediately after returning back from the field to the laboratory, all collected samples were stored in a refrigerated room $\left(T\right.$ below $\left.5^{\circ} \mathrm{C}\right)$ until the time of analysis. The subsequent analyses for the first set of samples were performed in Jordan, after reduction of the sample water into $\mathrm{H}_{2}$ by using the zinc method for $\delta^{2} \mathrm{H}$ analysis (Tanweer 1993), and by equilibrating a small amount of the sample water with a reference $\mathrm{CO}_{2}$ gas for $\delta^{18} \mathrm{O}$ analysis, and analysing the resulting $\mathrm{H}_{2}$ and $\mathrm{CO}_{2}$ gases using a Delta-E Finnigan Mat mass spectrometer. The stable isotope analyses for the remaining set of samples were performed in the Geology Department of AECS, by equilibrating a $5 \mathrm{ml}$ of subsample with small amounts of separate reference gases $\left(\mathrm{CO}_{2}\right.$ and $\left.\mathrm{H}_{2}\right)$, and analysing the resulting gases using a Finnigan Mat Delta Plus mass spectrometer. The measurement accuracy of $\delta^{18} \mathrm{O}$ and $\delta^{2} \mathrm{H}$ in both laboratories are better than $\pm 0.1 \%$ and $\pm 1.0 \%$ vs. VSMOW, respectively (Kattan 2006). The three IAEA standards (VSMOW, GISP and SLAP) were used for the calibration of stable isotope results, and the measured isotope ratios were expressed in the $\delta$ notation $(\%)$ relative to VSMOW, defined as

$$
\delta=\left[\left(R_{\text {sam }}-R_{\text {std }}\right) / R_{\text {std }}\right] \times 1000,
$$

where $R$ is the isotopic ratio $\left({ }^{2} \mathrm{H} /{ }^{1} \mathrm{H}\right.$ or $\left.{ }^{18} \mathrm{O} /{ }^{16} \mathrm{O}\right)$ and the sam and std indices denote the sample and the standard, respectively. 
Table 2. Comparison between average and amount-weighted mean (bold) $\delta^{18} O, \delta^{2} H$, and deuterium excess (d-excess) values of rainfalls collected from 16 Syrian stations during the period 1989-2006.

\begin{tabular}{|c|c|c|c|c|c|}
\hline Station & Sampling periods & $N^{*}$ & $\delta^{18} \mathrm{O}(\%)$ & $\delta^{2} \mathrm{H}(\%)$ & $d$-excess $(\%)$ \\
\hline Aleppo & Dec 1989-May1992 & 10 & $-5.8 \pm 3.4(-\mathbf{7 . 4} \pm \mathbf{0 . 3})$ & $-32 \pm 20(-\mathbf{4 0} \pm \mathbf{2 . 4})$ & $14 \pm 9(\mathbf{1 8 . 9} \pm \mathbf{0 . 8})^{* *}$ \\
\hline \multirow[t]{2}{*}{ Al-Kounietra } & Dec 1989-Apr1990 & 5 & $-5.9 \pm 2.8(-\mathbf{7 . 0} \pm \mathbf{0 . 1})$ & $-28 \pm 17(-\mathbf{3 3} \pm \mathbf{1 . 1})$ & $19 \pm 8(\mathbf{2 2 . 7} \pm \mathbf{1 . 2})$ \\
\hline & Dec 2003-Apr 2006 & 15 & & & \\
\hline Al-Nabk & Dec 2003-Apr 2006 & 16 & $-5.5 \pm 4.9(-\mathbf{6 . 5} \pm \mathbf{0 . 5})$ & $-31 \pm 31(-\mathbf{3 6} \pm \mathbf{2 . 5})$ & $13 \pm 13(\mathbf{1 6 . 7} \pm \mathbf{0 . 3})$ \\
\hline Al-Raqqa & Dec 1991-May 1992 & 5 & $-5.1 \pm 3.3(-\mathbf{6 . 4} \pm \mathbf{0 . 5})$ & $-26 \pm 16(-\mathbf{3 3} \pm \mathbf{4 . 2})$ & $15 \pm 11(\mathbf{1 9 . 0} \pm \mathbf{1 . 5})$ \\
\hline Al-Suwieda & Dec 1989-May 1993 & 14 & $-6.3 \pm 2.6(-\mathbf{7 . 3} \pm \mathbf{0 . 2})$ & $-29 \pm 16(-\mathbf{3 4} \pm \mathbf{2 . 1})$ & $21 \pm 7(\mathbf{2 3 . 7} \pm \mathbf{1 . 1})$ \\
\hline Bab-Janeh & Dec 1992-Apr 1993 & 5 & $-7.3 \pm 2.0(-\mathbf{7 . 8} \pm \mathbf{0 . 1})$ & $-38 \pm 13(-\mathbf{4 0} \pm \mathbf{0 . 9})$ & $20 \pm 4(\mathbf{2 2 . 9} \pm \mathbf{1 . 3})$ \\
\hline \multirow[t]{2}{*}{ Bloudan } & Dec 1989-Apr 1993 & 10 & $-7.8 \pm 2.8(-\mathbf{8 . 8} \pm \mathbf{0 . 1})$ & $-42 \pm 21(-\mathbf{4 8} \pm \mathbf{0 . 9})$ & $20 \pm 5(\mathbf{2 2 . 3} \pm \mathbf{0 . 9})$ \\
\hline & Dec 2003-Apr 2006 & 21 & & & \\
\hline \multirow[t]{2}{*}{ Damascus } & Dec 1989-Apr 1993 & 10 & $-6.3 \pm 3.7(-\mathbf{7 . 3} \pm \mathbf{0 . 3})$ & $-35 \pm 25(-\mathbf{3 9} \pm \mathbf{2 . 6})$ & $15 \pm 9(\mathbf{1 9 . 2} \pm \mathbf{0 . 8})$ \\
\hline & Dec 2003-Apr 2006 & 20 & & & \\
\hline Arneh & Nov 1991-May 1993 & 12 & $-6.9 \pm 3.3(-\mathbf{8 . 6} \pm \mathbf{0 . 2})$ & $-39 \pm 19(-\mathbf{4 7} \pm \mathbf{1 . 2})$ & $16 \pm 9(\mathbf{2 1 . 9} \pm \mathbf{1 . 0})$ \\
\hline \multirow[t]{2}{*}{ Homs } & Dec 1989-May 1993 & 10 & $-5.6 \pm 2.3(-\mathbf{6 . 3} \pm \mathbf{0 . 1})$ & $-28 \pm 14(-\mathbf{3 1} \pm \mathbf{0 . 7})$ & $17 \pm 7(\mathbf{1 9 . 5} \pm \mathbf{1 . 3})$ \\
\hline & Dec 2003-Apr 2006 & 19 & & & \\
\hline \multirow[t]{2}{*}{ Idleb } & Dec 1992-May 1993 & 10 & $-5.5 \pm 2.6(-\mathbf{6 . 6} \pm \mathbf{0 . 2})$ & $-30 \pm 16(-\mathbf{3 6} \pm \mathbf{3 . 6})$ & $14 \pm 6(\mathbf{1 6 . 8} \pm \mathbf{1 . 2})$ \\
\hline & Jan 2004-Apr 2006 & 10 & & & \\
\hline Izraa & Dec 1989-Apr 1993 & 14 & $-6.6 \pm 2.0(-7.7 \pm \mathbf{0 . 2})$ & $-32 \pm 13(-\mathbf{3 8} \pm \mathbf{0 . 3})$ & $21 \pm 6(\mathbf{2 3 . 4} \pm \mathbf{1 . 3})$ \\
\hline \multirow[t]{2}{*}{ Jarablous } & Dec 1991-May 1993 & 10 & $-5.7 \pm 2.7(-\mathbf{6 . 4} \pm \mathbf{0 . 5})$ & $-31 \pm 17(-\mathbf{3 5} \pm \mathbf{1 . 6})$ & $15 \pm 8(\mathbf{1 7 . 0} \pm \mathbf{1 . 0})$ \\
\hline & Jan 2004-Apr 2006 & 14 & & & \\
\hline Palmyra & Dec 1989-Mar 1993 & 14 & $-5.3 \pm 4.0(-\mathbf{5 . 8} \pm \mathbf{0 . 6})$ & $-28 \pm 27(-\mathbf{2 9} \pm \mathbf{4 . 8})$ & $14 \pm 5(\mathbf{1 7 . 8} \pm \mathbf{1 . 9})$ \\
\hline Qatana & Dec 2003-Apr 2006 & 15 & $-6.5 \pm 2.6(-\mathbf{7 . 6} \pm \mathbf{0 . 1})$ & $-35 \pm 17(-\mathbf{4 1} \pm \mathbf{1 . 1})$ & $16 \pm 7(\mathbf{1 9 . 8} \pm \mathbf{1 . 2})$ \\
\hline \multirow[t]{2}{*}{ Tartous } & Dec 1989-Apr 1993 & 10 & $-4.9 \pm 2.1(-\mathbf{5 . 8} \pm \mathbf{0 . 2})$ & $-23 \pm 13(-\mathbf{2 8} \pm \mathbf{1 . 2})$ & $16 \pm 5(\mathbf{1 8 . 6} \pm \mathbf{1 . 1})$ \\
\hline & Dec 2003-Apr 2006 & 21 & & & \\
\hline All stations & Dec 1989-Apr 2006 & 290 & $-6.0 \pm 3.0(-\mathbf{7 . 2} \pm \mathbf{0 . 2})$ & $-32 \pm 20(-\mathbf{3 7} \pm \mathbf{1 . 2})$ & $16 \pm 5(\mathbf{2 0 . 6} \pm \mathbf{1 . 3})$ \\
\hline
\end{tabular}

$N^{*}$ : Number of collected rainfall samples from each station during the two sampling periods.

** Amount-weighted mean errors were estimated according to Gatz and Smith (1995).

Quality assurance procedures, according to the ISO/IEC 17025, are strictly adhered to all AECS labs, and the isotopic analysis results are periodically verified through the participation in the different analysis comparison programs, managed by either the IAEA or other local and international organisations.

\section{Results and discussion}

\subsection{Stable isotope ratios in precipitation}

The stable isotope ratios of all rainfall data set in Syria ranges from $-14.6 \%$ to $+7.4 \%$, with an average of $-6.0 \pm 3 \%$, and from $-101 \%$ to $+35 \%$, with an average of $-32 \pm 20 \%$, for $\delta^{18} \mathrm{O}$ and $\delta^{2} \mathrm{H}$, respectively. As the isotopic composition of $P$ is to some extent a function of rainfall density, the amount-weighted mean value that takes into consideration this effect during any monitoring period can be calculated by using the following equation (Yurtsever and Gat 1981):

$$
C_{\mathrm{w}}=\sum_{i}^{n}\left[P_{i} \cdot C_{i}\right] / \sum_{i}^{n}\left[P_{i}\right],
$$

where $C_{\mathrm{w}}$ is the amount-weighted mean; $P_{i}$ is the monthly $P$-amount and $C_{i}$ is the isotopic composition of rainfall for the month $i$.

Table 2 summarises the averages and amountweighted mean values of $\delta^{18} \mathrm{O}$ and $\delta^{2} \mathrm{H}$ of all rainfall samples collected from all stations in Syria. A comparison of averages and amount-weighted mean values calculated for the overall data set reveals that the amount-weighted mean $\delta^{18} \mathrm{O}$ and $\delta^{2} \mathrm{H}$ values are always lower than the average values in all stations. For example, the difference in $\delta^{18} \mathrm{O}$ values varies from $0.5 \%$ (Palmyra) to $1.6 \%$ (Aleppo). This deviation is primarily due to the so-called ' $P$ amount effect', discussed later in this paper. The errors related to the determination of the amountweighted means in $\delta^{18} \mathrm{O}$ and $\delta^{2} \mathrm{H}$ values were lower than $0.5 \%$ and $5 \%$, respectively (table 2 ).

The rainfalls over the mountainous stations (Arneh, Bab-Janeh, Bloudan and Qatana) are 
isotopically characterised by the most depleted values $\left(\delta^{18} \mathrm{O}<-6.5 \%\right.$ and $\delta^{2} \mathrm{H}<-35^{\circ} \%$ ), likely because of their relative higher elevations and minor evaporation compared to the other stations of lower $P$-amount and RH values. However, although the Arneh and Bloudan stations have nearly similar altitudes, the rainfalls at Bloudan are isotopically more depleted than those at Arneh, most probably because of different sampling periods. Rainfalls at both stations are isotopically the most depleted in the country simply because of their specific high elevation $(H>1500 \mathrm{~m}$ a.s.l.). In contrast, the rainfalls at Tartous, Homs and Palmyra stations are isotopically the most enriched, likely because of their lower altitudes $(H<500 \mathrm{~m}$ a.s.l.), and possibly because of the evaporation of raindrops. The westerly strong winds, largely prevailed within the coastal inter-mountains, such as the so-called 'Homs corridor', could facilitate the movement of the enriched air masses, locally formed over the MS (Gat et al. 2003), to proceed eastward towards such inland stations. The isotopic composition of $P$ in the remaining stations (Aleppo, Al-Kounietra, Al-Suwieda, Damascus and Idleb) occupies an intermediate position between both the above-mentioned groups.

\subsection{Deuterium excess}

Determination of the deuterium excess ( $d$-excess or d) value in $P$ samples is a useful tool for delineating the effect of secondary evaporation (Gat 1996). This parameter, which was defined by Dansgaard (1964) as $d$-excess $=\delta^{2} \mathrm{H}-8 \delta^{18} \mathrm{O}$, reflects the isotopic composition of the initial water vapour, vapour recycling over the continents and kinetic isotope fractionation by evaporation or condensation during non-equilibrium processes (AraguásAraguás et al. 2000; Cappa et al. 2003; Froehlich et al. 2005; Managave et al. 2016).

The $d$-excess value of the overall data set in Syria varies from $\leq 0 \%$ in samples highly evaporated or of a low $P$-amount to $+30 \%$ in the rainfalls of southern Syria. Similarly, the calculated amount-weighted mean $d$-excess values of $P$ are clearly higher than the average values in all stations by a difference of $\approx 2-6 \%$, with an error lower than $1.9 \%$ (table 2). This difference may indicate that the intensive rains are mostly due to humid air masses affected by interaction or exchange with the enriched $(d>$ $22 \%$ ) MS moisture (Gat et al. 2003). Accordingly, the amount-weighted mean value will be more representative than the average value, especially when using the stable isotope methods for the estimation of groundwater recharge rates, likely as intensive rains quantitatively contribute more than the low rains to such processes.

The southern stations (Al-Suwieda, Al-Kounietra and Izraa) dispose impressively the highest $d$-excess values $(d>20 \%)$ in the country because of the stronger interactions with the MS moisture, fairly as a high percentage $(>46 \%)$ of prevalent winds from the SW direction. Previous measurements of the isotopic composition of moisture over the MS show that the intensive evaporation and sea-air interaction near the coast lead to large $d$-excess values $(d>30 \%)$ in the atmospheric water vapours, while the warm and dry air masses coming from North Africa were mostly of a lower $d$-excess value close to $20 \%$ (Gat et al. 2003). The rainfalls over the western mountainous stations (Bab-Janeh, Bloudan and Arneh), located at a short distance from the coast, have also contributed to the increase in $d$-excess values $(d>21 \%)$, reflecting the influence of MS moisture. However, the rains at the northern and interior inland regions (Al-Nabk, Idleb, Jarablous and Palmyra), which remarkably have lower $d$-excess values $(d<18 \%$ oo are less affected by the exchange with the MS moisture, but probably by stronger interactions with the continental moisture of lower $d$-excess values $(d=10 \%)$. The rainfalls over the other inland stations dispose intermediate $d$-excess values ranging between $17 \%$ and $21 \%$.

Although the Idleb and Al-Nabk stations are located at a short distance from the coast compared to Palmyra, the $d$-excess value for both stations is clearly lower than that of Palmyra. This means that the Palmyra area is more open to an exchange with the MS moisture. The mountain series (Mt Anti-Lebanon and the Coastal mountains) may play a role in reducing the direct circulation of the MS moisture from proceeding towards such inland stations. Although the Al-Nabk station is fairly located in a high area $(H>1290 \mathrm{~m}$ a.s.l. $)$, its rainfall has distinctly the lowest $d$-excess value $\left(d<17^{\circ} \%\right)$, most probably because of its specific weather condition, as it receives the lowest $P$-amount in the country.

In all cases, the average $d$-excess value for the overall data set of rainfall in Syria $(17 \pm 8 \%$ is significantly higher than the value $(10 \%)$ or the newer value $(11.27 \%$ oo , respectively, given by Craig (1961) and Rozanski et al. (1993) for the global meteoric water. This value is clearly closer to the 


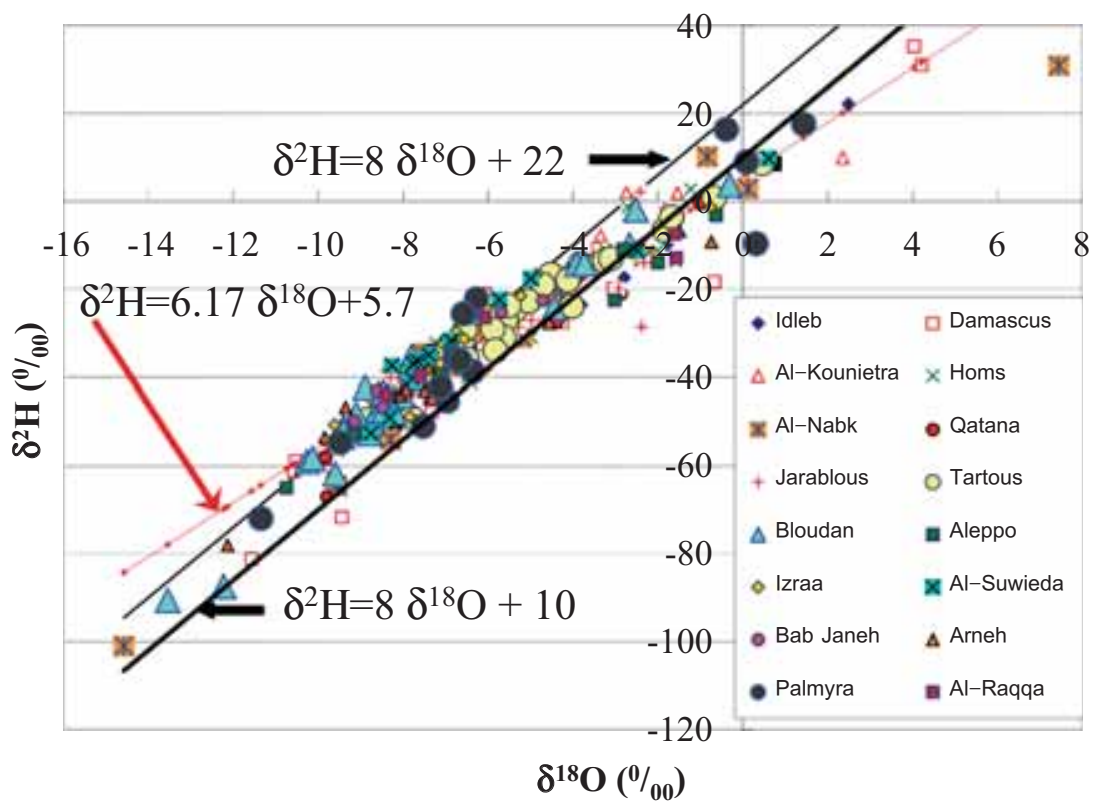

Figure 4. Relationship between monthly $\delta^{2} \mathrm{H}$ and $\delta^{18} \mathrm{O}$ values of all $P$ samples collected in Syria during the period $1989-2006$.

common value $\left(22^{\circ} \%\right)$, given by Nir (1967) for $P$ in the eastern Mediterranean regions, and strongly fits with the recent findings by Bajjali (2012) for a number of Jordanian stations. According to this author, this parameter was around $22 \%$ in the earlier $P$ samples collected during the period 1965 1969, while it was significantly higher than $24^{\circ} \%$ in the recent rainfall series that occurred during 1987-2005.

\subsection{Local meteoric water line}

The most frequent relationship between $\delta^{2} \mathrm{H}$ and $\delta^{18} \mathrm{O}$ values, or the so-called 'global meteoric water line' (GMWL) was defined by Craig (1961) as $\delta^{2} \mathrm{H}=8 \delta^{18} \mathrm{O}+10$. This equation was later modified by Rozanski et al. (1993), who suggested two empirical regression lines, given by the following equations:

$$
\delta^{2} \mathrm{H}=(8.17 \pm 0.06) \delta^{18} \mathrm{O}+(10.35 \pm 0.65)
$$

for the long-term annual arithmetic mean values and

$$
\delta^{2} \mathrm{H}=(8.20 \pm 0.07) \delta^{18} \mathrm{O}+(11.27 \pm 0.65)
$$

for the long-term annual amount-weighted mean values.

The importance of this relationship occurs in the slope and the intercept values of the fitting line, as any divergence in the slope value from the equilibrium condition value $(\approx 8 \%)$ determines the degree of fractionation in the ${ }^{2} \mathrm{H}$ and ${ }^{18} \mathrm{O}$ values, while the line intercept value defines significantly the above-mentioned $d$-excess parameter, or modification due to evaporation or change of climate conditions (Araguás-Araguás et al. 2000). Figure 4 illustrates the relationship $\delta^{2} \mathrm{H}-\delta^{18} \mathrm{O}$ for all rainfall samples in Syria. This plot clearly shows that most of the rainfall sample points, mainly those of depleted values $\left(\delta^{18} \mathrm{O}<-6^{\circ} \%\right.$ and $\delta^{2} \mathrm{H}<-30 \%$ o $)$ are regrouped close to the Mediterranean meteoric water line (MMWL), defined by Nir (1967) as $\delta^{2} \mathrm{H}=8 \delta^{18} \mathrm{O}+22$. The remaining rainfall sample points, representing fairly the evaporated $P$ samples $\left(\delta^{18} \mathrm{O}>-4^{\%} \%\right)$, tend to fall on the GMWL. The rainfall sample points of all data fit nicely on a least squares regression line, or the so-called 'local meteoric water line', approximated by the following equation:

$$
\begin{aligned}
\delta^{2} \mathrm{H}= & (6.17 \pm 0.1) \delta^{18} \mathrm{O}+(5.66 \pm 0.7) \\
& \text { with } R^{2}=0.92 \text { and } N=290 .
\end{aligned}
$$

The line slope $(6.17 \pm 0.1)$ deviates significantly from the value (8), given the natural condensation of water vapour under equilibrium conditions (Craig 1961). This means that the raindrops of the samples with $\delta^{18} \mathrm{O}>-4 \%$ and $\delta^{2} \mathrm{H}>-10 \%$ had re-evaporated during their falling (Dincer and Payne 1971). However, a few samples with very depleted isotope values tend to match with the GMWL. These samples that mainly belong to 


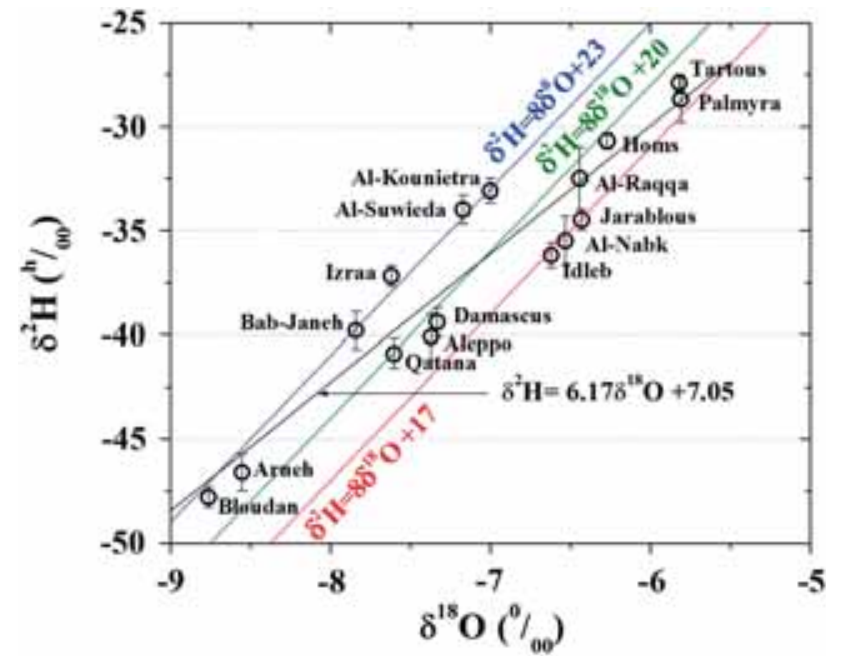

Figure 5. Relationship between amount-weighted mean $\delta^{2} \mathrm{H}$ and $\delta^{18} \mathrm{O}$ values in $P$ in all Syrian stations. Black open circles denote station points and their error bars. Black line is the linear regression fitting all station points. Blue, olive and red lines are linear regressions with a constant slope (8) and different $Y$-intercept values $(23 \%, 20 \%$ and $17 \%$, respectively), arbitrarily drawn to approximately fit with the different station points.

Bloudan, Damascus, Arneh and Al-Nabk stations, are all due to the Khamasin air masses. These rainfalls usually reflect the so-called 'continental effect', characterised by a progressive decrease in stable isotope values with increasing distance from the coast or inland distance (Eriksson 1983). The depleted rainfall samples match a line slope value of 8 , meaning that these rains are not, or even slightly, affected by evaporation, as the re-evaporation of raindrops leads to lower slope values (Rozanski et al. 1993). The projection of all representative station points in the $\delta^{2} \mathrm{H}-\delta^{18} \mathrm{O}$ diagram, established on the basis of amount-weighted mean values during the entire sampling period (figure 5) remarkably shows that all station points are regrouped between two empirical lines having a slope of 8 , but with different $Y$-intercept values, ranging between $17 \%$ and $23 \%$. Similarly, the equation of the least squares regression line fitting all station points, or the LMWL, is approximated as

$$
\begin{gathered}
\delta^{2} \mathrm{H}=(6.17 \pm 0.6) \delta^{18} \mathrm{O}+(7.05 \pm 4.1) \\
\text { with } R^{2}=0.90 \text { and } N=16 .
\end{gathered}
$$

The line slope $(6.17 \pm 0.6)$ of this equation is identical to that of equation (3) $(6.17 \pm 0.1)$, while the intercept value $(7.05 \pm 4.1 \%)$ is significantly higher by $\approx 1.4 \%$. This means that the enriched rainfalls underwent similar evaporation conditions. This plot clearly shows that the rainfalls at Bloudan and Arneh stations are isotopically the most depleted in $\delta^{2} \mathrm{H}$ and $\delta^{18} \mathrm{O}$ values, whereas those at Palmyra and Tartous stations are the most enriched. The distribution of the representative station points in this diagram permits the differentiation between the following three groups:

1. The rainfalls at the mountainous stations (Bloudan, Arneh and Bab-Janeh) and the southern stations (Al-Kounietra, Al-Suwieda and Izraa) fitting a regression line with a $Y$ intercept value $>20 \%$.

2. The rainfall at the coastal station (Tartous) and the interior inland stations (Al-Nabk, Idleb, Jarablous and Palmyra) fitting a regression line with a $Y$-intercept value $<20 \%$.

3. The rainfall at the remaining interior inland stations (Aleppo, Al-Raqqa, Damascus, Homs and Qatana) matching a regression line with an intermediate $Y$-intercept value of $\approx 20 \%$.

The rainfalls of the first group are characterised by a $d$-excess value very close to the value $(22 \%)$, given by Nir (1967). Hence, this group of rainfalls is the closest to the MMWL likely because of the short distance to the MS coast. Noting here that the principal data used for defining the MMWL was referred to Bet-Dagan station that disposes the longest registries of isotopic data in the eastern Mediterranean region (IAEA-WMO 2006). The slope value (6.17) differs significantly from the value (8.26), previously given by Kattan (1997b) for the LMWL in Syria, based on a collection of isotopic data covering nine stations during a short mentoring period (1989-1990). This slope also differs from the value (7.8), previously given for the regional meteoric water line (RMWL) in Syria and Jordan (Kattan 1997b). However, this slope is rather close to the value (6.6), given by AlCharideh and Abou Zakhem (2010) for the LMWL in Syria, based on data collection from 12 stations during 2000-2003. This slope is very close to the value (6.3), given for the LMWL in Lebanon (Aouad-Rizk et al. 2005) and also the recent value (6.27), given by Bajjali (2012) for the LMWL in Jordan.

Table 3 illustrates the regression parameters calculated for the relationship $\delta^{2} \mathrm{H}-\delta^{18} \mathrm{O}$ for all stations, based on the monthly $\delta^{2} \mathrm{H}$ and $\delta^{18} \mathrm{O}$ values in $P$. The line slope values vary from $4.8 \pm 0.6$ 
Table 3. Regression parameters for the linear relationships between monthly $\delta^{2} H$ and $\delta^{18} O$ values in $P$ samples collected at 16 stations in Syria.

\begin{tabular}{lcrrrr}
\hline Station & Slope & $Y$-intercept & $N$ & $R^{2}$ & $P$-value* \\
\hline Aleppo & $5.61 \pm 0.42$ & $0.36 \pm 2.80$ & 10 & 0.96 & $<\mathbf{0 . 0 0 0 1}$ \\
Al-Kounietra & $5.82 \pm 0.48$ & $6.53 \pm 3.09$ & 20 & 0.89 & $<\mathbf{0 . 0 0 0 1}$ \\
Al-Nabk & $6.02 \pm 0.48$ & $1.89 \pm 3.15$ & 16 & 0.93 & $<\mathbf{0 . 0 0 0 1}$ \\
Al-Raqqa & $4.81 \pm 0.58$ & $1.83 \pm 3.36$ & 5 & 0.96 & $\mathbf{0 . 0 0 3 6}$ \\
Al-Suwieda & $5.97 \pm 0.49$ & $8.26 \pm 3.33$ & 14 & 0.93 & $<\mathbf{0 . 0 0 0 1}$ \\
Bab-Janeh & $6.27 \pm 0.59$ & $8.42 \pm 4.43$ & 5 & 0.97 & $\mathbf{0 . 0 0 1 8}$ \\
Bloudan & $7.16 \pm 0.31$ & $13.17 \pm 2.53$ & 31 & 0.95 & $<\mathbf{0 . 0 0 0 1}$ \\
Damascus & $6.42 \pm 0.36$ & $5.29 \pm 2.62$ & 30 & 0.92 & $<\mathbf{0 . 0 0 0 1}$ \\
Arneh & $7.31 \pm 0.44$ & $15.00 \pm 3.35$ & 12 & 0.94 & $<\mathbf{0 . 0 0 0 1}$ \\
Homs & $5.74 \pm 0.38$ & $4.33 \pm 2.33$ & 29 & 0.89 & $<\mathbf{0 . 0 0 0 1}$ \\
Idleb & $5.99 \pm 0.28$ & $3.50 \pm 1.14$ & 20 & 0.97 & $<\mathbf{0 . 0 0 0 1}$ \\
Izraa & $5.98 \pm 0.59$ & $7.45 \pm 4.07$ & 14 & 0.89 & $<\mathbf{0 . 0 0 0 1}$ \\
Jarablous & $5.89 \pm 0.45$ & $2.86 \pm 2.82$ & 24 & 0.89 & $<\mathbf{0 . 0 0 0 1}$ \\
Palmyra & $6.58 \pm 0.61$ & $6.80 \pm 3.96$ & 14 & 0.91 & $<\mathbf{0 . 0 0 0 1}$ \\
Qatana & $6.42 \pm 0.55$ & $6.17 \pm 3.79$ & 15 & 0.91 & $<\mathbf{0 . 0 0 0 1}$ \\
Tartous & $6.12 \pm 0.28$ & $6.88 \pm 1.47$ & 31 & 0.94 & $<\mathbf{0 . 0 0 0 1}$ \\
Syria & $6.17 \pm 0.11$ & $5.66 \pm 0.74$ & 290 & 0.92 & $<\mathbf{0 . 0 0 0 1}$ \\
\hline
\end{tabular}

*Boldface $P$-values indicate a significant relationship.

(Al-Raqqa) to $7.3 \pm 0.4$ (Arneh). The rainfalls at Bloudan and Arneh stations have the closest slope value to that of the rainfall formed under equilibrium conditions $(\approx 8)$, likely because of the low evaporation rates and high elevations of these stations. Both stations dispose, as well, high $Y$ intercept values $(13-15 \pm 3 \%)$. However, lower line slopes $(4.8 \pm 0.6<$ slope $<7 \pm 0.4)$ were found for the remaining stations, with also low $Y$-intercept values, ranging between $\approx 0.4 \pm 3 \%$ (Aleppo) and $\approx 8.4 \pm 4 \%$ (Bab-Janeh). This range means that the rainfalls at these stations were rather subject to the evaporation of different intensities, depending on the humidity or aridity conditions prevalent around the considered areas. The rainfalls at the Aleppo, Al-Nabk, Al-Raqqa and Jarablous stations show the lowest line slope $(<6 \pm 0.5)$ and the lowest $Y$-intercept $(<3 \pm 3 \%)$ values, likely because of the higher evaporation rates. The equation $\left(\delta^{2} \mathrm{H}=\right.$ $5.82 \pm 0.5 \delta^{18} \mathrm{O}+6.53 \pm 3.1$ ), estimated for the relationship $\delta^{2} \mathrm{H}-\delta^{18} \mathrm{O}$, for the Al-Kounietra rainfall is highly similar to that of Bet-Dagan station, defined as $\delta^{2} \mathrm{H}=5.48 \delta^{18} \mathrm{O}+6.87$ (IAEA-WMO 2006).

\subsection{Temperature effect}

Table 4 summarises the regression parameters calculated for the $\Delta \delta^{18} \mathrm{O}-\Delta T$ and $\Delta \delta^{2} \mathrm{H}-\Delta T$ relationships, based on the mean monthly data for different Syrian stations. The effect of surface air $T$ on the isotopic composition of $P$ is shown by significant enrichments in both $\delta^{18} \mathrm{O}$ and $\delta^{2} \mathrm{H}$ values. With the exception of Palmyra data, where the coefficient $\Delta \delta^{18} \mathrm{O} / \Delta T$ was remarkably elevated $\left(\approx 0.7 \pm 0.2 \%{ }^{\circ} /{ }^{\circ} \mathrm{C}\right)$, this coefficient ranges in the case of the remaining stations between $\approx 0.2 \pm 0.08 \%{ }^{\circ} /{ }^{\circ} \mathrm{C}$ (Bloudan) and $\approx 0.6 \pm 0.14 \%{ }^{\circ} /{ }^{\circ} \mathrm{C}$ (Al-Kounietra), with an average value of $0.34 \pm$ $0.03 \%{ }_{00} /{ }^{\circ} \mathrm{C}$ for overall rainfall data. Similarly, the $T$ effect on the $\delta^{2} \mathrm{H}$ parameter is also high $(\approx 4 \pm$ $1 \% /{ }^{\circ} \mathrm{C}$ ) for Palmyra, while it ranges from $\approx 1.2 \pm$ $0.6 \% /{ }^{\circ} \mathrm{C}$ (Bloudan) to $\approx 3.5 \pm 0.9$ (Al-Kounietra), with an average value of $\approx 2 \pm 0.2 \%{ }^{\circ} /{ }^{\circ} \mathrm{C}$ for all stations. The sample points representing the cold months $\left(T<10^{\circ} \mathrm{C}\right)$ are less scattered compared to those representing the months of higher $T$ values (figure 6a). The reason that the isotopic composition of $P$ during the warm months was largely scattered is either due to the evaporation of rain droplets during their falling on the land, such as the case of the samples collected during March and April of 1993, 2004 and 2005, or because of the continental effect that affected a fewer number of samples, especially those characterised by very depleted values, which belong to the Khamasin depressions that occurred during April 1990, January 2004 and 2005 and February 2006.

The coefficient $\Delta \delta^{18} \mathrm{O} / \Delta T$ is generally small $\left(<0.2 \pm 0.2 \% /{ }^{\circ} \mathrm{C}\right)$ in the case of the mountainous stations (Arneh, Al-Nabk, Bab-Janeh, Bloudan and Qatana); intermediate $\left(0.3-0.4 \pm 0.2 \% /{ }^{\circ} \mathrm{C}\right)$ 


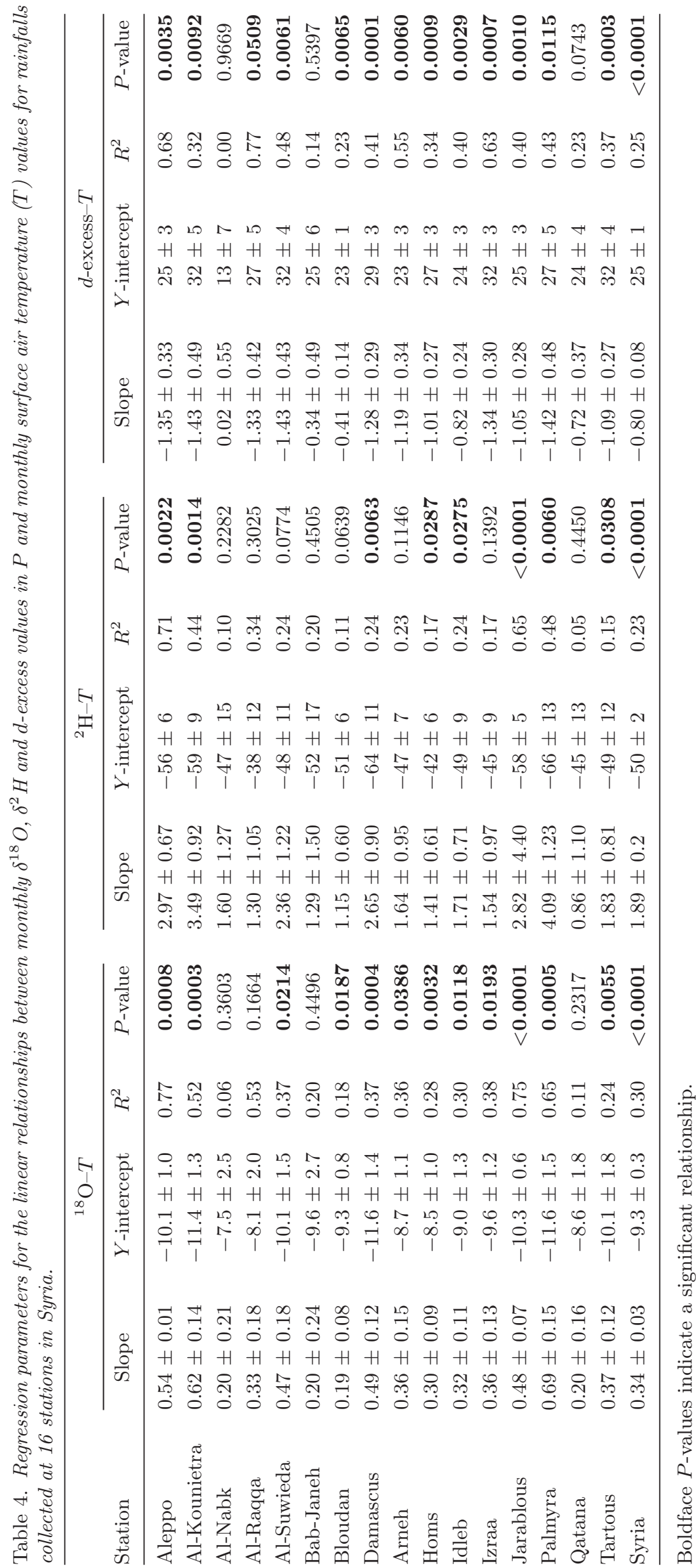



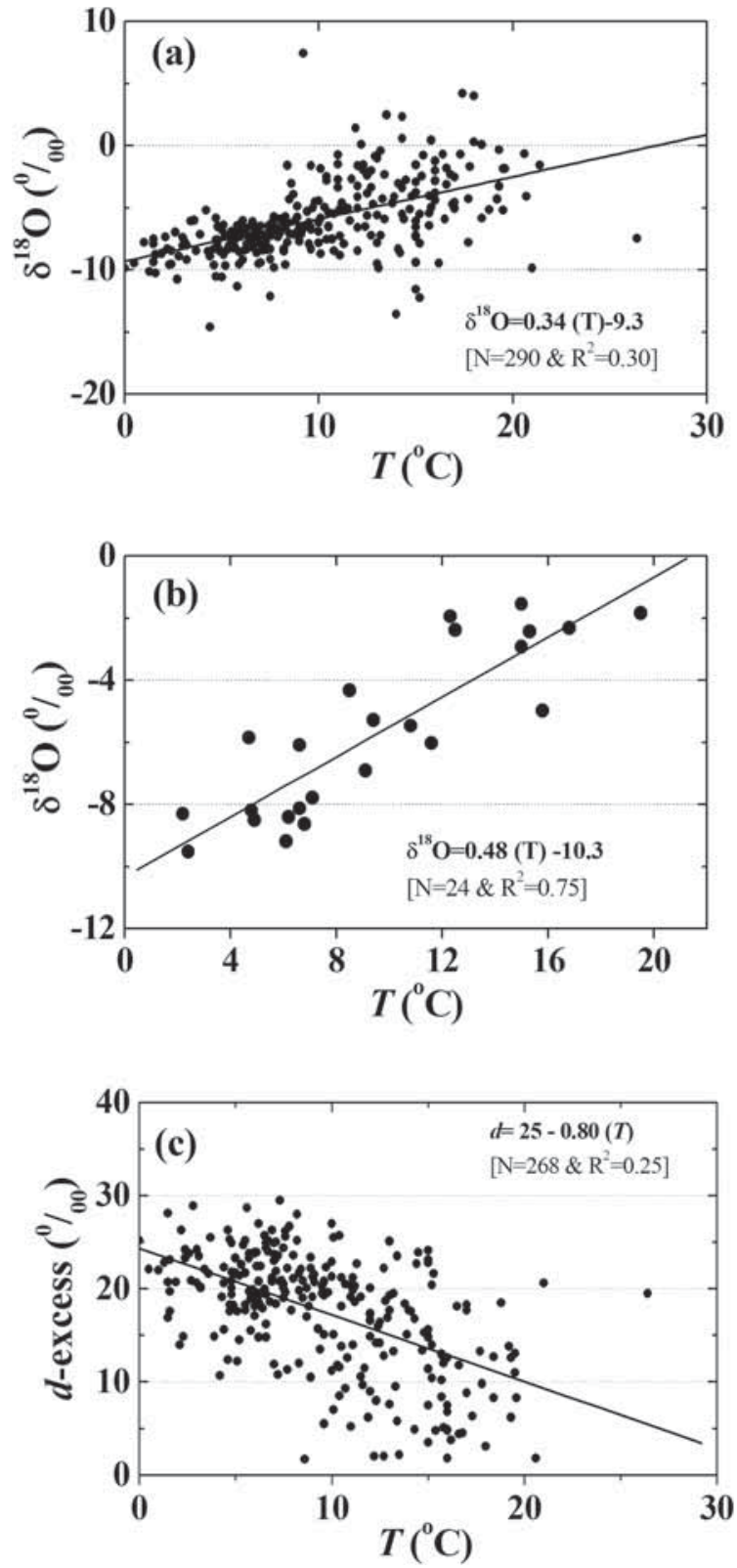

Figure 6. Relationship between monthly $\delta^{18} \mathrm{O}$ and $T$ values of all $P$ samples in Syria (a); between monthly $\delta^{18} \mathrm{O}$ and $T$ values of $P$ samples at Jarablous station (b); and between $d$-excess and $T$ values of all $P$ samples in Syria (c). Black lines denote linear fittings and their equations.

for the Al-Raqqa, Homs, Idleb and Tartous stations; and clearly much higher than $0.4 \pm$ $0.2 \% /{ }^{\circ} \mathrm{C}$ in the case of Aleppo, Al-Kounietra, Al-Suwieda, Damascus, Palmyra and Jarablous (figure $6 \mathrm{~b}$ ). The $T$ effect on the overall data in Syria is represented by an average enrichment of $0.34 \pm$ $0.03 \% /{ }^{\circ} \mathrm{C}$ and $1.89 \pm 0.2 \% /{ }^{\circ} \mathrm{C}$ for $\delta^{18} \mathrm{O}$ and $\delta^{2} \mathrm{H}$, respectively. The coefficient $\Delta \delta^{18} \mathrm{O} / \Delta T$ is slightly higher than the value $\left(0.25 \%{ }_{00} /{ }^{\circ} \mathrm{C}\right)$, estimated for $P$ in Lebanon (Aouad-Rizk et al. 2005), likely as the Lebanese stations are all located at high elevations compared to the Syrian stations. However, this coefficient is rather close to the value $\left(0.4 \pm 0.02 \% /{ }_{00}^{\circ} \mathrm{C}\right)$, given as an average value for the long-term monthly data of the GNIP network (Rozanski et al. 1993).

With the exception of the Al-Nabk station, for which the correlation coefficient for the relationship $d$-excess- $T$ was distinctly very weak $\left(R^{2} \approx 0\right)$, the line slopes for this relationship in the case of the remaining stations were all negative and rather of significant values (table 4). The decrease in the $d$-excess value in the case of the mountainous stations (Arneh, Bab-Janeh and Bloudan) was $\approx 0.35-0.40 \pm 0.3 \% /{ }^{\circ} \mathrm{C}$ and about $\approx 1.4 \pm 0.5 \% /{ }^{\circ} \mathrm{C}$ for Al-Kounietra, Al-Suwieda and Palmyra, with an average value of $-0.8 \pm 0.08 \% /{ }^{\circ} \mathrm{C}$ for all stations (figure 6c). The Al-Nabk station shows a different isotopic signature simply because of its special geographical location, as it lies at a high altitude between two mountain series
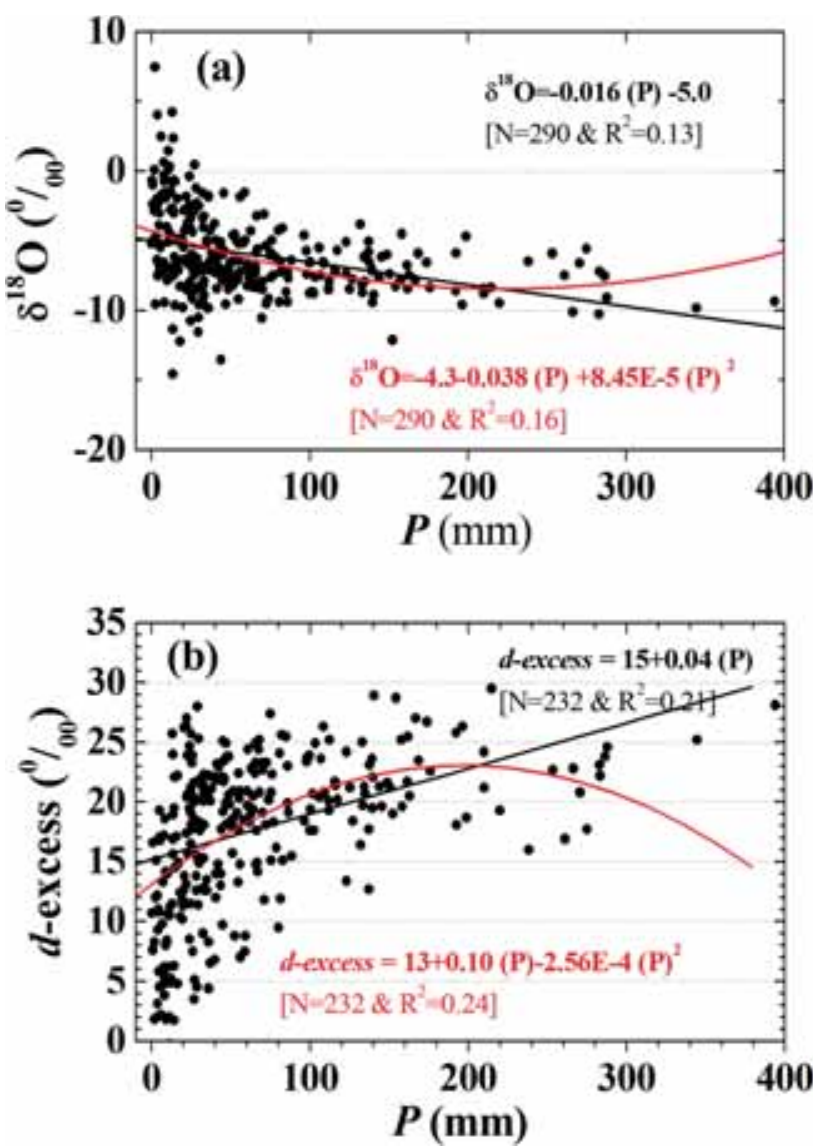

Figure 7. Relationship between monthly $\delta^{18} \mathrm{O}$ and $P$ amount values (a) and between monthly $d$-excess and $P$-amount values (b) of all samples in Syria. Black and red lines refer to linear and polynomial fittings and their equations, respectively. 
(Mt Anti-Lebanon and South-Palmyrides). Extrapolation of the relationship $d$-excess $-T$ to a $T$ value of $\approx 0^{\circ} \mathrm{C}$ reveals that the $Y$-intercept value for the Al-Nabk station will be $\approx 13 \pm 7 \%$, while it ranges between $23 \pm 3 \%$ (Arneh and Bloudan) and $32 \pm 4 \%$ (Al-Suwieda), with an average value of $25 \pm 1 \%$ for all stations (table 4). This result also proves that the rainfalls at the Al-Nabk station are less affected by the MS moistures, usually producing $d$-excess values higher than $15 \%$ (Gat et al. 2003). In all cases, the range of $T$ effect on the stable isotope composition of $P$ in Syria highly agrees with the published values given for $P$ in most Mediterranean countries (IAEA 2005b).

\subsection{Amount effect}

Amount effect is traditionally interpreted as the depletion of heavy stable isotope ratios with increasing $P$-amount values (Dansgaard 1964; Lee and Fung 2008). However, this depletion is not always valid, as a significant isotopic enrichment is also possible to be associated with high $P$-amounts, such as it was observed in southern subtropical Brazil (Cruz et al. 2005). This effect, which primarily depends on the meteorological conditions at the time of rain falling ( $T$ and $\mathrm{RH}$ ), is usually due to several factors: (i) decreasing of the isotopic composition of the condensate in a cloud as cooling and raining proceed; (ii) quick equilibrium of small raindrops with ambient water vapour and $T$ conditions compared to larger raindrops; and (iii) fast evaporation of small raindrops during their falling on the land surface compared to larger raindrops (Rozanski et al. 1993; Scholl et al. 2009). The best correlation coefficients for the monthly $\delta^{18} \mathrm{O}-\mathrm{P}$ relationship were found for Hong Kong $\left(R^{2}=0.71\right)$ and New Delhi $\left(R^{2}=0.45\right)$ stations (Rozanski et al. 1993). Nonetheless, this important relationship is not consistent and appears as a useless indicator for rain events affected by evaporation, likely because of the secondary evaporation effect that can mask the original isotopic signature (Liotta et al. 2008).

The amount effect on the Syrian rainfalls is generally reflected by negative correlations between the concentrations of the stable isotopes $\left({ }^{18} \mathrm{O}\right.$ and ${ }^{2} \mathrm{H}$ ) and monthly $P$-amounts (figure $7 \mathrm{a}$ ), accompanied by a positive correlation between $d$ excess values and monthly $P$ amounts (figure $7 \mathrm{~b}$ ). These plots show that the sample points representing small monthly $P$-amounts $(<50 \mathrm{~mm})$ are much scattered compared to rainfalls of higher $P$-amount values $(>100 \mathrm{~mm})$. Similarly, the relationship $d$-excess $-P$ clearly demonstrates that the rainfalls of high $P$-amount values $(>100 \mathrm{~mm})$ usually dispose larger $d$-excess values $(>12 \%)$. Although the correlation coefficient $\left(R^{2}\right)$ values of the second-order polynomial curves for the relationships $\delta^{18} \mathrm{O}-P$ and $d$-excess- $P$ (16 and 24 , respectively) were statistically higher than those of the linear regressions (13 and 21, respectively), it seems that the linear function fits much better with the sample data of high $P$-amount values (>300 mm).

Table 5 reports the regression parameters for the relationships between monthly mean $\delta^{18} \mathrm{O}, \delta^{2} \mathrm{H}$ and $d$-excess values in $P$ and monthly $P$-amount values of rainfall for all stations. The correlation coefficients for most of the stations were generally moderated $\left(R^{2}<0.4\right)$. Although the correlation coefficients for the relationships $\delta^{18} \mathrm{O}-P$ and $\delta^{2} \mathrm{H}-$ $P$ were rather high $\left(0.6<R^{2}<0.4\right)$ for the Aleppo
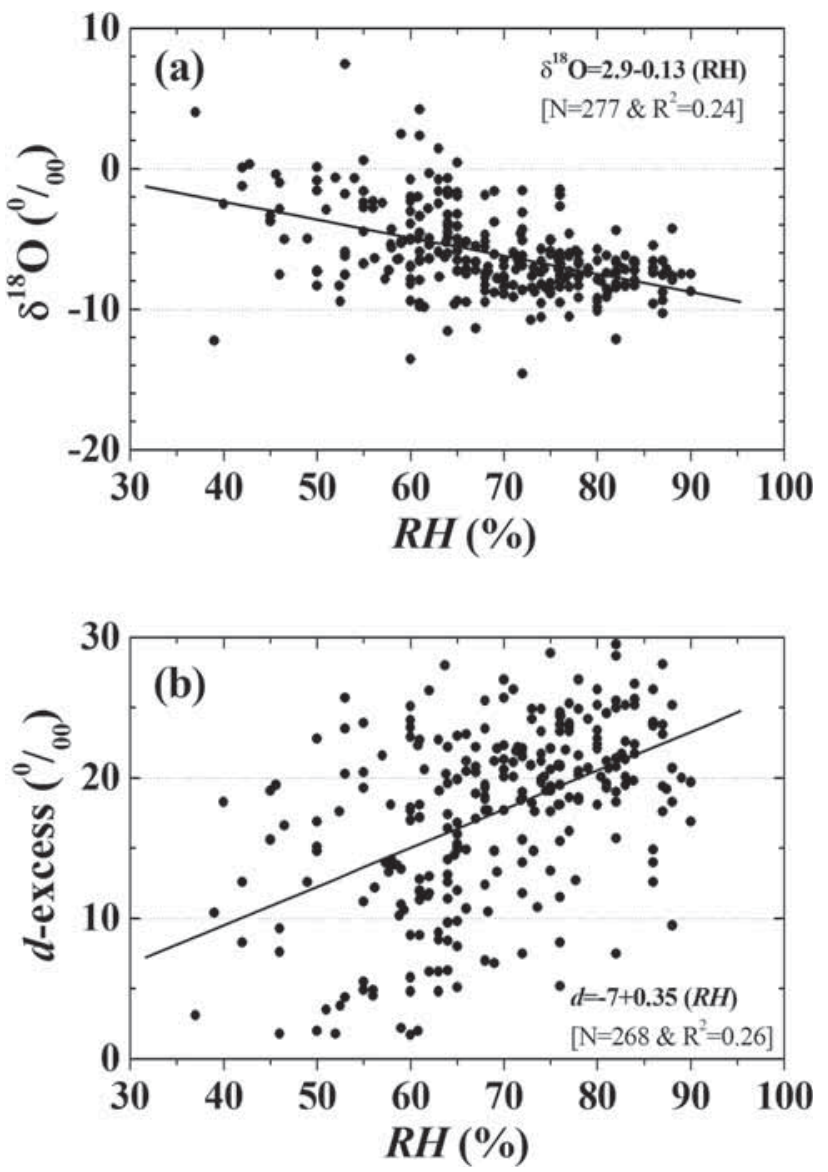

Figure 8. Relationship between monthly $\delta^{18} \mathrm{O}$ and $\mathrm{RH}$ values (a) and monthly $d$-excess and $\mathrm{RH}$ values (b) of all $P$ samples in Syria. Black lines denote linear fittings and their equations. 


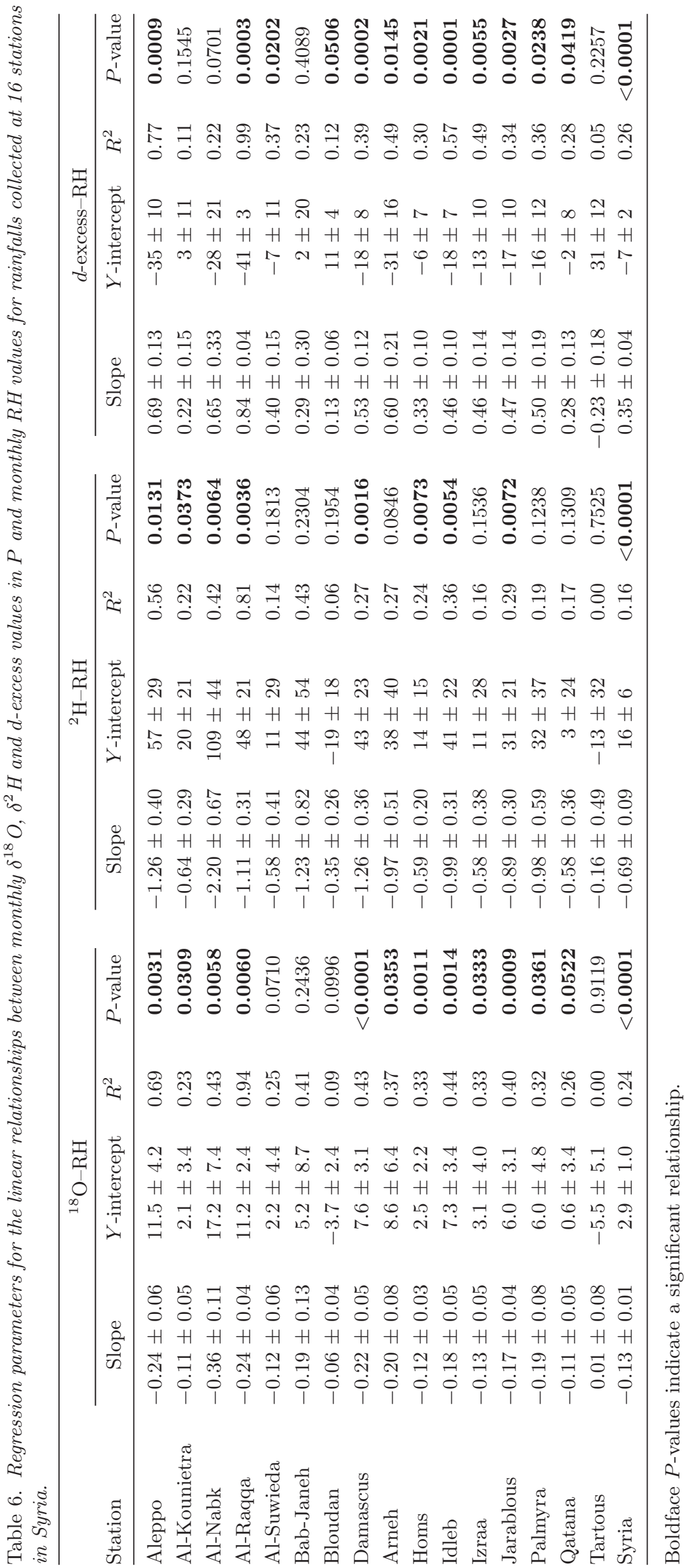


and Al-Raqqa stations, these regressions are still weak because of the lower number of collected samples from both stations. The slope value of the regression lines differs from station to station, ranging in the case of the $\delta^{18} \mathrm{O}-P$ relationship between $-0.01 \pm 0.01$ (Bab-Janeh) and $-0.21 \pm 0.14$ (AlNabk), with an average value of $-0.016 \pm<0.01$ for all stations. The rather high slope value that was observed for Al-Nabk is mostly because this station receives the lowest $P$-amount in the country. This station is also characterised by a distinct isotopic pattern, as it was reflected in the high slope value $(-0.86 \pm 0.92)$ for the relationship $\delta^{2} \mathrm{H}-P$ (table 5). The lowest $Y$-intercept values for the relationship $d$-excess $-P(<3 \%)$ were found for the Al-Raqqa, Al-Nabk and Aleppo stations. All these stations are supposed to receive rainfalls more subject to secondary evaporation, likely as they are all placed under dryer environments.

\subsection{Air humidity effect}

Changes in $\mathrm{RH}$ value principally affect the kinetic isotopic fractionation. This parameter can thus reflect the different isotopic enrichments due to evaporation of rainfalls. The higher the $\mathrm{RH}$ value, the lower the evaporation value, the lower the kinetic fractionation of water and vice versa (Clark and Fritz 1997). The RH effect on the isotopic composition of $P$ in Syria is represented by depletions in the monthly $\delta^{18} \mathrm{O}$ and $\delta^{2} \mathrm{H}$ values, accompanied by an increase in the monthly $d$-excess value with increasing monthly $\mathrm{RH}$ values (figure 8). The data shows that when $\mathrm{RH}$ values are higher than $80 \%$, the $\delta^{18} \mathrm{O}$ values in most of the rainfall samples are in the range between $-12 \%$ and $-6 \%$ (figure $8 \mathrm{a}$ ), and between $-70 \%$ and $-30 \%$ for the $\delta^{2} \mathrm{H}$ values, while most of these samples have generally higher $d$-excess values $(15 \%<$ $d<30 \%$ ). In contrast, when $\mathrm{RH}$ values drop to less than $50 \%$, the $d$-excess value of most of the $P$ samples becomes clearly below $20 \%$ (figure $8 \mathrm{~b}$ ).

Table 6 illustrates the regression parameters for the relationships between monthly $\delta^{18} \mathrm{O}, \delta^{2} \mathrm{H}$ and $d$-excess values of $P$ and the corresponding monthly average $\mathrm{RH}$ values measured at these stations. Accordingly, it can be observed that the correlation coefficients for the relationships $\delta^{18} \mathrm{O}-$ $\mathrm{RH}$ and $\delta^{2} \mathrm{H}-\mathrm{RH}$ were of no importance for Tartous $\left(R^{2} \approx 0\right)$, very weak for Bloudan $\left(R^{2}<0.1\right)$ and fairly much higher $\left(R^{2}>0.8\right)$ for Al-Raqqa. This means that the $\mathrm{RH}$ effect is more pronounced or effective in the case of the inland stations, such as Aleppo, Al-Raqqa, Damascus, Idleb and Jarablous. Statistically, no significant difference was found between the linear and the second-order polynomial correlation coefficients.

\subsection{Altitude effect}

Altitude effect is physically a $T$ dependence, and thus as the terrain altitude becomes more and more higher, the air $T$ value drops down, and water vapour condensation is accompanied by a
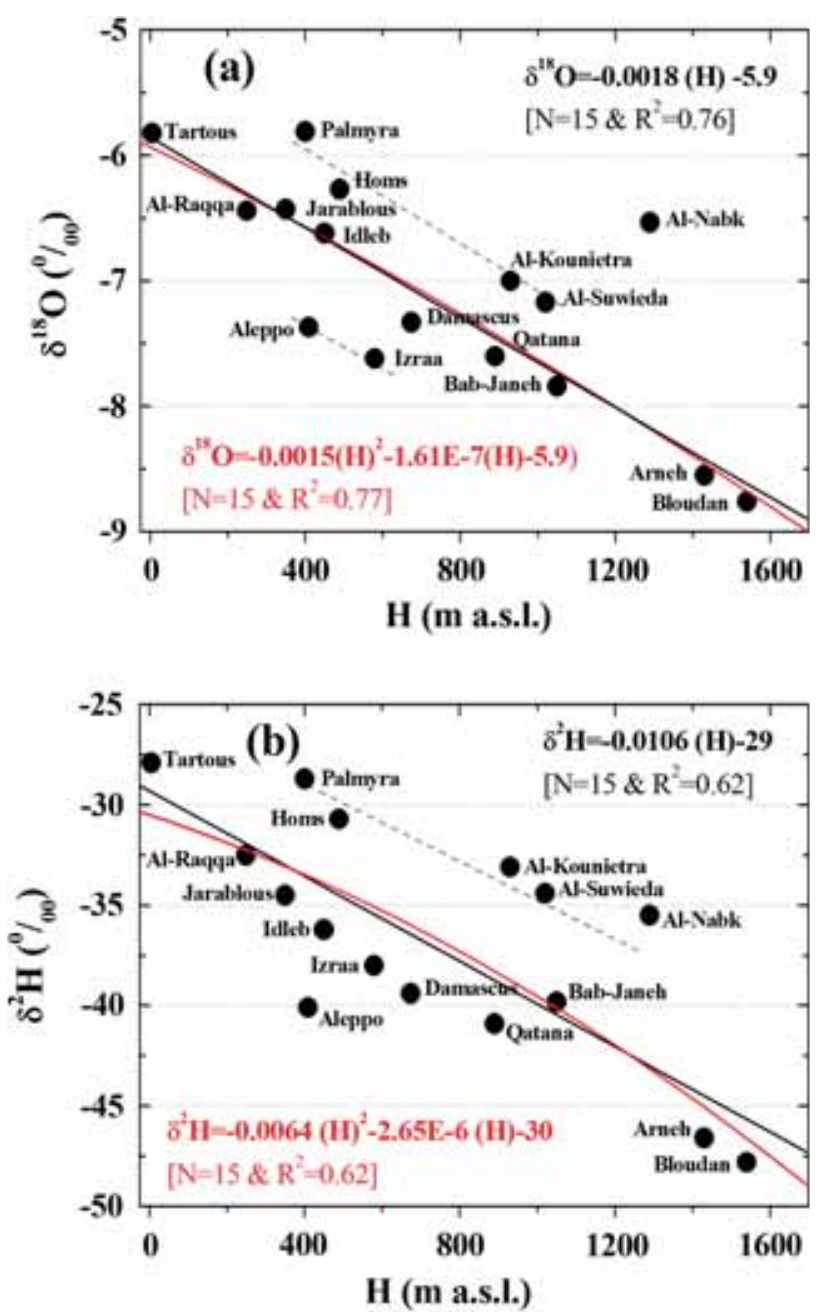

Figure 9. Relationship between the amount-weighted mean $\delta^{18} \mathrm{O}$ and altitude $(H)$ values $(\mathbf{a})$ and amount-weighted mean $\delta^{2} \mathrm{H}$ and $H$ values (b) of $P$ samples at 16 stations in Syria. Black bold circles denote station points. Black and red lines refer to linear and polynomial fittings and their equations, respectively. Black dashed lines are arbitrary lines of similar slopes drawn to fit with the number of station points. 

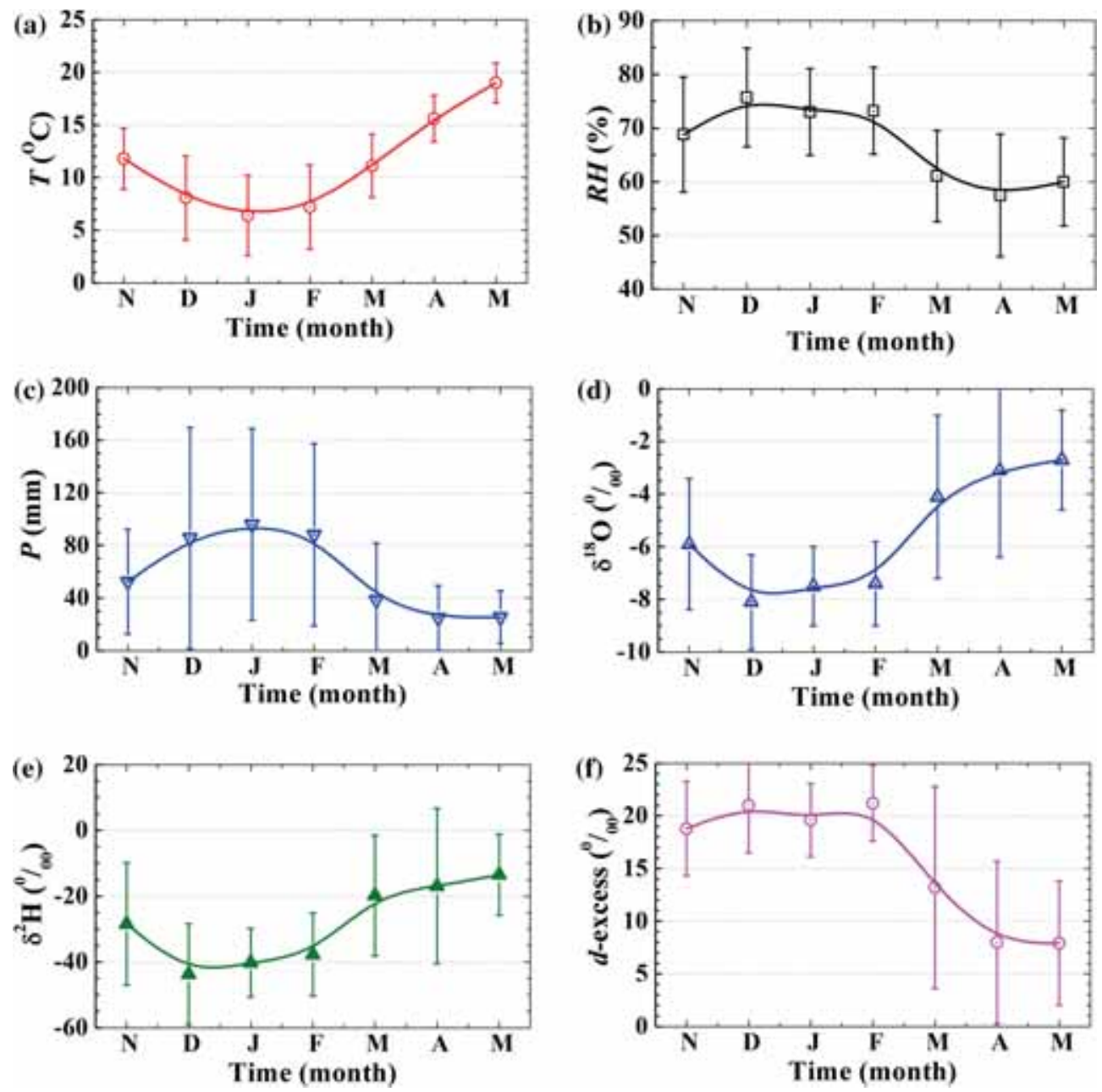

Figure 10. Temporal variability in average and STD values for the meteorological parameters: $T$ (a), RH (b) and $P$ (c) values; and for $\delta^{18} \mathrm{O}(\mathbf{d}), \delta^{2} \mathrm{H}(\mathbf{e})$ and $d$-excess (f) values of $P$ samples collected during the rainy season (November-May).

progressive depletion in the concentration of heavy stable isotopes. This effect highly depends on the topography and local weather conditions, and it is an important measure to explain the large spatial variability of such isotopes in the rainfall waters. However, while this effect is remarkably very important in mountainous catchment areas (Kumar et al. 2010), its role in the tropical areas is usually less pronounced (Sturm et al. 2007; Peng et al. 2010; Windhorst et al. 2013). Determination of the altitude effect has been proved to be a useful tool in many hydrogeological studies, especially for identifying groundwater recharge zones (Kattan 1997a; Gonfiantini et al. 2001; Harrington et al. 2002).

Figure 9 shows the relationships between the amount-weighted mean $\delta^{18} \mathrm{O}$ and $\delta^{2} \mathrm{H}$ values of $P$ in all the stations as a function of the corresponding elevations $(H, \mathrm{~m}$ a.s.l.). With the exception of the Al-Nabk station that disposes a distinct isotopic pattern, the representative station points for the remaining stations fit nicely between two linear regression lines:

$$
\begin{aligned}
\delta^{18} \mathrm{O}= & -0.0018 \pm 0.0003 \times(H)-5.9 \pm 0.3 \\
& \text { with } R^{2}=0.76 \text { and } N=15, \\
\delta^{2} \mathrm{H}= & -0.0110 \pm 0.0024 \times(H)-29 \pm 2 \\
& \text { with } R^{2}=0.62 \text { and } N=15 .
\end{aligned}
$$

The plots clearly show that the stable isotope values in Aleppo rainfalls are rather more depleted compared to those in the stations of similar altitudes, likely because of further exchange with the continental water vapour or recycling of the local moisture. This behaviour is strongly reflected in the very low $Y$-intercept value $(0.36 \pm 2.8 \%)$ for 
the relationship $\delta^{2} \mathrm{H}-\delta^{18} \mathrm{O}$ (table 3 ). Although the rainfalls at the Palmyra, Homs, Al-Kounietra and Al-Suwieda stations are isotopically more enriched compared to the remaining stations, the representative points for these stations fit much better with another regression line having an identical slope value. The rainfalls at these later stations are suggested to be more subjected to additional enrichment by evaporation.

Based on the above-mentioned regressions (equations 5 and 6), the altitude effect in Syria is characterised by a progressive depletion of $-0.18 \pm$ $0.03 \%$ and $-1.1 \pm 0.24 \%$ per $100 \mathrm{~m}$ for $\delta^{18} \mathrm{O}$ and $\delta^{2} \mathrm{H}$, respectively. The estimated lapse rate for the $\delta^{18} \mathrm{O}$ gradient fits well with the range $(-0.15 \%$ to $-0.6 \%$ per $100 \mathrm{~m})$, given by Rozanski et al. (1993) for the GNIP stations. However, the gradient in $\delta^{2} \mathrm{H}$ depletion is slightly lower than the range $(-1.5 \%$ oo to $-4.0 \%$ per $100 \mathrm{~m})$, given by Yurtsever and Gat (1981) for the same rainfall category. The lapse rates reported for the depletions in $\delta^{18} \mathrm{O}$ and $\delta^{2} \mathrm{H}$ values are also slightly lower than the previous gradients $(-0.23 \%$ and $-1.6 \%$ per $100 \mathrm{~m}$ for $\delta^{18} \mathrm{O}$ and $\delta^{2} \mathrm{H}$, respectively), given for $P$ in Syria (Kattan 1997b). In contrast, the $\delta^{18} \mathrm{O}$ gradient is very close to the lapse rate $\left(-0.19^{\circ} \%\right.$ per $\left.100 \mathrm{~m}\right)$, previously published for the Damascus basin (Prizgonov et al. 1988). The estimated altitude effect is generally in good agreement with the range given for the $\delta^{18} \mathrm{O}$ gradient $(-0.10 \%$ to $-0.23 \%$ per 100 $\mathrm{m})$, reported for $P$ in most Mediterranean countries (Aouad-Rizk et al. 2005; IAEA 2005b; Saad et al. 2005; Bajjali 2012).

\subsection{Seasonal effect}

Temporal changes in stable isotope concentrations of $P$ between minimum and maximum values during a year commonly reflect the so-called 'seasonal effect'. This effect is usually the result of changes in the temporal ambient weather conditions, mainly the values of the major meteorological parameters $(T, \mathrm{RH}$ and $P)$, in which the meteoric water is produced. Seasonal variability also depends on the successive modifications of the isotopic composition, fairly by evaporation, such as that affecting the rainstorms along their trajectories or during their falling on the land surface (Smith 1992). Systematic seasonal variations in the stable isotope ratios in $P$ are strongly linked to changes in the air $T$ values. Hence, most of the storm events occurring in winter are isotopically more depleted compared to summer rainfalls, likely because of air $T$ raising, and thus gradual isotopic enrichments by evaporation (Dansgaard 1964).

Figure 10 illustrates the temporal variations in the monthly averages and standard deviation (STD) values for the major parameters $(T, \mathrm{RH}$ and $P)$ and the stable isotopes $\left(\delta^{18} \mathrm{O}, \delta^{2} \mathrm{H}\right.$ and $d$-excess $)$ in $P$ in Syria during the rainy season (NovemberMay). Clearly, it can be observed that the monthly averages in $T$ value vary from $6.4^{\circ} \mathrm{C}$ (January) to $19.0^{\circ} \mathrm{C}$ (May), with a STD value lower than $4^{\circ} \mathrm{C}$. During this period, the monthly $\mathrm{RH}$ averages fluctuate around $60-76 \%$, with an STD value of $8-11 \%$. The high $\mathrm{RH}$ values $(>70 \%)$ occur generally during December to February, while the low values $(\mathrm{RH}<60 \%)$ possibly occur by the beginning of March. The monthly average of the $P$-amount value changes from $<50 \mathrm{~mm}$ in November to
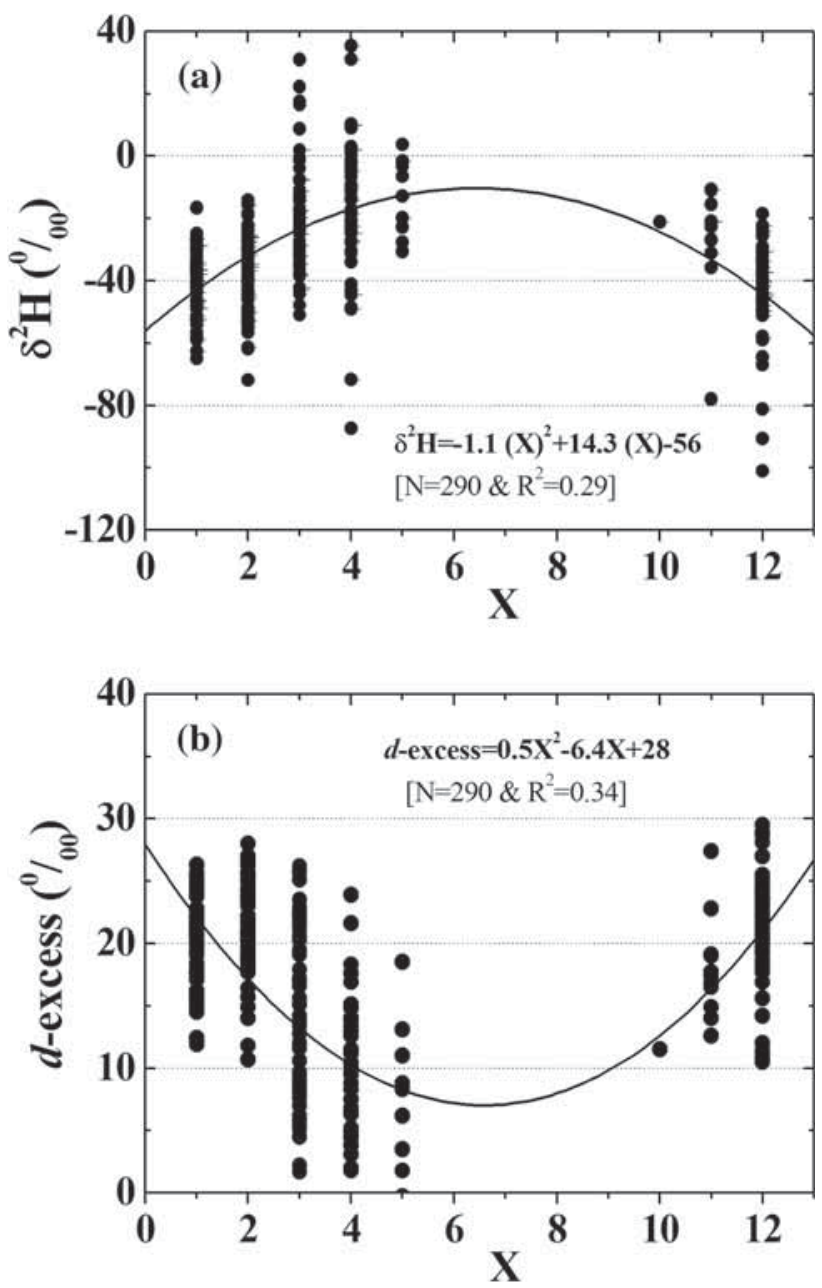

Figure 11. Temporal variability in monthly $\delta^{2} \mathrm{H}$ (a) and $d$-excess (b) values as functions of the month number $(X$, i.e., $X=1$ for January; $X=3$ for March; and $X=12$ for December, etc.) for all $P$ samples in Syria. Black curves are polynomial fittings and their equations that are only valid for the rainy season (November-May). 


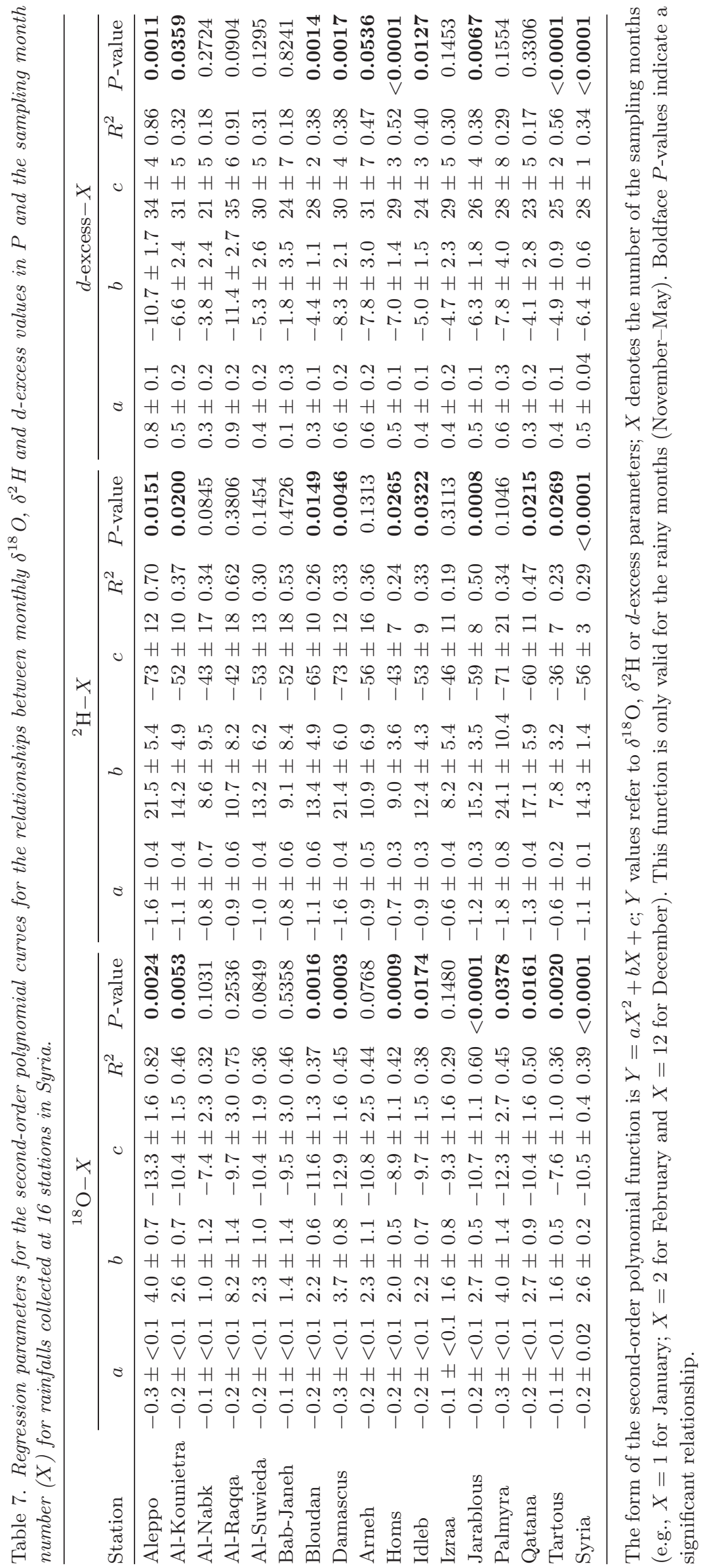


$>100 \mathrm{~mm}$ in January, with clearly a similar trend to that of the monthly averages in the $\mathrm{RH}$ value. During April-May, the monthly averages of the $P$ amount gradually becomes $<25 \mathrm{~mm}$. A perfectly good accordance can be observed between the temporal variation patterns of the monthly averages in the $\delta^{18} \mathrm{O}$ and $\delta^{2} \mathrm{H}$ values. This accordance clearly proves that the stable isotope ratios of $P$ in Syria were remarkably the most depleted during December-February, likely when the monthly average $T$ value is the lowest, and also when the monthly averages of the $P$-amount and $\mathrm{RH}$ values are both the highest. In contrast, the temporal variation of the monthly averages of $d$-excess value is completely inversely related to those of $\delta^{18} \mathrm{O}$ and $\delta^{2} \mathrm{H}$ evolutions. A rather good accordance exists between the temporal variation patterns of the $P$-amount, $\mathrm{RH}$ and $d$-excess parameters. Hence, it can be seen that the high $d$-excess values $(>19 \%$ oo generally occur during the months of heaviest rains and elevated $\mathrm{RH}$ values. At the end of the rainy season (May), the monthly averages in the $d$-excess value progressively drop down to less than $8 \%$. These results show that the $T$ effect is not only the major cause for producing such seasonal isotope variability, but other factors, such as $P$-amount and $\mathrm{RH}$ effects, along with trajectories of air masses, may equally contribute altogether to give such seasonal isotopic changes (Rozanski et al. 1993). In all cases, it seems necessary to consider all these factors, likely the influence of the humid air masses coming over the MS, which can strongly contribute to produce the isotopic signature of meteoric waters in the eastern Mediterranean countries (Gat et al. 2003; IAEA 2005b).

Attempts were also made to find the best fit for characterising the monthly variations in the $\delta^{18} \mathrm{O}$, $\delta^{2} \mathrm{H}$ and $d$-excess values of $P$ in Syria during the period from October to May. As it was previously concluded in many works, the second-order polynomial function $\left(Y=f\left[X^{2}, X\right]\right)$ for the relationships between $\delta^{18} \mathrm{O}, \delta^{2} \mathrm{H}$ and $d$-excess $(Y)$ values and the month number $(X)$ of the year (e.g., $X=1$ for January, $X=2$ for February, and $X=12$ for December, etc.) is theoretically the best fit for such cases (Lykoudis et al. 2010).

Figure 11 illustrates the distributions of monthly $\delta^{2} \mathrm{H}$ and $d$-excess values in function of the month number $(X)$ during which the rainfall samples were collected, together with the fitted polynomial curves for these parameters, while table 7 reports the main characteristics of the fitted curves for the different Syrian stations. The correlation coefficients for the above relationships are generally moderated $\left(29<R^{2}<0.39\right)$. However, high coefficient values $\left(R^{2}>0.60\right)$ were found for the relationship $\delta^{18} \mathrm{O}-X$ for the Aleppo, Al-Raqqa, Qatana and Jarablous stations. In contrast, a low correlation coefficient $\left(R^{2}=0.28\right)$ was found for the same relationship for the Izraa station. Similarly, strong coefficient values $\left(R^{2}>0.50\right)$ were also reported for the relationships $\delta^{2} \mathrm{H}-X$ and $d$-excess $-X$ for the Aleppo and Al-Raqqa stations. The importance of this determination occurs in the constants $a$ and $c$ values of the fitted curve $\left(Y=a X^{2}+b X+c\right)$, that are both negatives in the case of the $\delta^{18} \mathrm{O}-X$ and $\delta^{2} \mathrm{H}-X$ relationships, and both positives in the case of the $d$-excess- $X$ relationship (table 7 ). The value of the constant (c) simply indicates that during the month $X=0$ (i.e., the end of December or the beginning of January), the $\delta^{18} \mathrm{O}$ and $\delta^{2} \mathrm{H}$ values of $P$ are isotopically the most depleted in all stations, ranging in the case of $\delta^{18} \mathrm{O}$ from $-7.4 \%$ (Tartous) to $-13.3 \%$ (Aleppo), likely because of low air $T$ values and high $\mathrm{RH}$ values during this time. In contrast, the values of the constant $(c)$ for the relationship $d$-excess $-X(22 \%<c<35 \%)$ are clearly much higher than the ordinary measured values in the rainfall samples $(d$-excess $<22 \%$ ). The values of this constant are also very depleted in the case of $\delta^{18} \mathrm{O}$ and $\delta^{2} \mathrm{H}$ and more enriched in the case of $d$-excess compared to the measured values. This constant may probably reflect the isotopic composition of the initial water vapours from which these rains were produced, or also the roles of the ambient meteorological conditions, mainly the effects of air $T$ and $\mathrm{RH}$ values in which the rainwater was formed. It is noteworthy to observe that the lowest $c$ values for the relationships $\delta^{18} \mathrm{O}-X$ and $\delta^{2} \mathrm{H}-X$ were distinctly found for Damascus, Aleppo and Palmyra stations, where a trend of a possible recycling of the local continental moisture may occur (Kattan 1997b).

\section{Conclusions}

The results obtained throughout this study primarily focused on the stable isotope ratios in rainfall waters from 16 stations in Syria and they highly contribute to a better understanding of the role of the different controlling factors such as isotope variability, mainly across the western parts of Syria. The major conclusions that can be drawn from this work are the following: 
- The amount-weighted means in $\delta^{18} \mathrm{O}$ and $\delta^{2} \mathrm{H}$ values are always lower than the average values in all stations, and constantly higher than the averages in the case of $d$-excess values. This significant difference strongly reflects the important role of the intensive air masses that originated from the NAO, the northern pole and the Siberian system, which are isotopically associated with the depleted $\delta^{18} \mathrm{O}$ and $\delta^{2} \mathrm{H}$ values.

- The rainfalls at the mountainous stations are isotopically the most depleted in $\delta^{18} \mathrm{O}$ and $\delta^{2} \mathrm{H}$ values, likely because of the lower air $T$ values at higher elevations, whereas the stations in southern Syria are remarkably characterised by the highest $d$-excess values $(>22 \%$ oo $)$, fairly because of the high percentage of the prevalent winds $(\approx 46 \%)$ from the SW direction, and thus a higher exchange with the enriched MS moisture. Due to the low elevation, the rainfall samples at Tartous and Palmyra stations are isotopically the most enriched in $\delta^{18} \mathrm{O}$ and $\delta^{2} \mathrm{H}$ values. The so-called 'Homs corridor' may facilitate the movement of the MS moisture to proceed towards Palmyra station, located in the central Syrian desert. However, the coastal mountain series and Mt Anti-Lebanon may play a role in blocking the direct circulation of the MS moisture to proceed eastward, mainly towards the Al-Nabk and Idleb stations, where the exchange with the continental moisture $(d$-excess $<10 \%$ ) becomes evidently more pronounced.

- The slope values for the LMWL in Syria, ranging from $4.8 \pm 0.6$ to $7.3 \pm 0.4$, with an average value of $6.17 \pm 0.1$, are in a good accordance with those in most Mediterranean countries. The line slope $(7.05 \pm 0.1)$, calculated based on the amount-weighted means, is the closest to that of the rain produced under equilibrium conditions $(\approx 8)$, meaning that the heaviest rains are usually less affected by evaporation compared to rains of lower $P$-amount values.

- The $T$ effect is generally shown by a progressive enrichment in the stable isotope ratios $\left(0.34 \pm 0.03 \%{ }_{00} /{ }^{\circ} \mathrm{C}\right.$ and $1.89 \pm 0.2 \%{ }^{\circ} /{ }^{\circ} \mathrm{C}$ for $\delta^{18} \mathrm{O}$ and $\delta^{2} \mathrm{H}$, respectively), accompanied by a notable decrease in the $d$-excess value $(-0.8$ $\left.\pm 0.08 \% /{ }^{\circ} \mathrm{C}\right)$ with $T$ increasing. The observed $\delta^{18} \mathrm{O} / \mathrm{T}$ gradient in Syria $\left(0.34 \pm 0.03 \%{ }_{00} /{ }^{\circ} \mathrm{C}\right)$ is very close to that of the GNIP value $\left(0.3 \%{ }^{\circ} /{ }^{\circ} \mathrm{C}\right)$, while it is slightly higher than that of Lebanon $\left(0.25 \% /{ }^{\circ} \mathrm{C}\right)$, as most of the Lebanese stations are all located at higher elevations and closer distances to the MS.

- The amount effect gradient is generally small in the case of the stations located close to the MS and moderated in the remaining stations. Although the Al-Nabk station is relatively close to the MS coast, its gradient is exceptionally very high, likely because of its specific weather condition, as it receives the lowest $P$ amount values in the country. The $\mathrm{RH}$ effect is shown by the depletions of $-0.13 \pm 0.01 \%$ and $-0.7 \pm 0.1 \%$ for $\delta^{18} \mathrm{O}$ and $\delta^{2} \mathrm{H}$, respectively, and by an enrichment of $\approx 0.35 \pm 0.04 \%$ in the $d$-excess value, with $1 \%$ increase in the RH value. The rainfalls with low $d$-excess values $(\approx 10 \%)$ are mostly associated with low $\mathrm{RH}$ values $(\approx 40 \%)$, while those of higher values $(d$ excess $>20 \%$ ) are usually combined with high $\mathrm{RH}$ values $(>80 \%)$.

- The altitude effect is shown by the depleted gradients of $-0.18 \pm 0.03 \%$ and $-1.1 \pm 0.24 \%$ for $\delta^{18} \mathrm{O}$ and $\delta^{2} \mathrm{H}$, respectively. The gradient in the $\delta^{18} \mathrm{O}$ value strongly agrees with the gradient value $(-0.19 \%)$, previously given for the Damascus basin, and fits well with the range $(-0.10 \%$ to $-0.23 \%)$, reported for $P$ in most Mediterranean countries. The seasonal effect is shown by depleted isotope values during winter (December-February), when air $T$ values drop down to less than $10^{\circ} \mathrm{C}$ and $\mathrm{RH}$ values become higher than $70 \%$. The temporal variation trend of the average $d$-excess values is completely in contrast to those of the average $\delta^{18} \mathrm{O}$ and $\delta^{2} \mathrm{H}$ values, with high $d$-excess values $(19-21 \%$ ) during the months of elevated $P$-amounts and high $\mathrm{RH}$ values and low $d$ excess values $(<8 \%)$ at the end of the rainy season.

- Although $T$ parameter is the principal factor that strongly controls the spatial and temporal isotope variability of $P$ in Syria, other factors, such as $P$-amount, $\mathrm{RH}$ and trajectories of air masses, can conjunctly play additional roles, but of less importance to that of $T$. The enriched MS moisture and secondary evaporation also have a further influence on the isotopic composition of $P$ in such a semiarid to arid country. Studying the variability of the stable isotope ratios in $P$ at a level of individual or single storm events would be necessary and most desirable for a better understanding of the influence of the different key parameters. 


\section{Acknowledgements}

The author would like to express his gratitude to Prof I Othman, Director General of AECS for his encouragement and kind permission to publish this paper. Thanks are also due to Prof W Rasoul-Agha for his comments and valuable remarks related to this work. Mrs P K Aggarwal and L AraguasAraguas from the IAEA organisation are deeply acknowledged for the useful assistance provided during the implementation of the IAEA coordinated research project (CRP contract No. 14053). The author is also indebted to the technical staff of the geology department at AECS for the numerous instances of assistance in the collection and analysis of rainfall samples.

\section{References}

Abou Zakhem B and Hafez R 2007 Chemical and isotopic composition of precipitations in Syria; AECS-G $\backslash$ RSS No. 729, Atomic Energy Commission of Syria, Damascus.

Aggarwal P K, Frohlich K, Kulkarni K M and Gourcy L L 2004 Stable isotope evidence for moisture sources in the Asian summer monsoon under present and past climate regimes; Geophys. Res. Lett. 31 L08203, https://doi.org/ 10.1029/2004GL019911.

Aizen V B, Aizen E M, Fujita K, Nikitin S, Kreutz K and Takeuchi N 2005 Stable-isotope time series and precipitation origin from firn cores and snow samples, Altai glaciers, Siberia; J. Glaciol. 51(175) 637-654.

Al-Charideh A R and Abou Zakhem B 2010 Distribution of tritium and stable isotopes in precipitation in Syria; Hydrol. Sci. J. 55(5) 1-13.

Al-Momani I F, Tuncel S, Eler U, Ortel E, Sirin G and Tuncel G 1995 Major ion composition of wet and dry deposition in the eastern Mediterranean basin; Sci. Total Environ. $16475-85$.

Aouad-Rizk A, Job J L, Najem W, Travi Y, Blavoux B and Gourcy L 2005 Oxygen-18 and deuterium contents over Mount Lebanon related to air mass trajectories and local parameters; In: Isotopic Composition of Precipitation in the Mediterranean Basin in Relation to Air Circulation Patterns and Climate (ed.) IAEA, TECDOC-1453, Vienna, pp. 75-82.

Araguás-Araguás L, Froehlich K and Rozanski K 2000 Deuterium and oxygen-18 isotope composition of precipitation and atmospheric moisture; Hydrol. Process. 14 1341-1355.

Bajjali W 2012 Spatial variability of environmental isotope and chemical content of precipitation in Jordan and evidence of slight change in climate; Appl. Water Sci. 2 271-283, doi https://doi.org/10.1007/s13201-012-0046-1.

Bowen G J and Revenaugh J 2003 Interpolating the isotopic composition of modern meteoric precipitation; Water Resour. 39(10) 1299.

Bowen G J and Wilkinson B 2002 Spatial distribution of delta O-18 in meteoric precipitation; Geology 30(4) 315318.
Cappa C D, Hendricks M B, DePaolo D J and Cohen R C 2003 Isotopic fractionation of water during evaporation; J. Geophys. Res. 108(D16) 4522-4534.

Clark I and Fritz P 1997 Environmental Isotopes in Hydrogeology; Lewis Publishers, Boca Raton, New York.

Craig H 1961 Isotopic variations in meteoric waters; Science 1331702.

Criss R E 1999 Principles of Stable Isotope Distribution; Oxford University Press, New York.

Cruz F W, Burns S J, Karmann I, Sharp W D, Vuille M, Cardoso A O, Ferrari J A, Silva Dias P L and Viana O 2005 Insolation-driven changes in atmospheric circulation over the past 116,000 years in subtropical Brazil; Nature $43463-66$.

Dansgaard W 1964 Stable isotopes in precipitation; Tellus 16 436-468.

Dincer I and Payne B R 1971 An environmental isotope study of the southwestern karst region of Turkey; J. Hydrol. 14 233-258.

Dutton A, Wilkinson B H, Welker J M, Bowen G J and Lohmann K C 2005 Spatial distribution and seasonal variation in ${ }^{18} \mathrm{O} /{ }^{16} \mathrm{O}$ of modern precipitation and river water across the conterminous United States; Hydrol. Process. 19 4121-4146, https://doi.org/10.1002/hyp.5876.

Eriksson E 1983 Stable isotopes and tritium in precipitation; In: Guidebook on Nuclear Techniques in Hydrology (ed.) International Atomic Energy Agency (IAEA), Technical Report Series No. 91, Vienna, pp. 19-33.

Fritz P and Fontes J Ch 1980 Handbook of Environmental Isotope Geochemistry 1. The terrestrial environment; Elsevier, Amsterdam.

Froehlich K F O, Gonfiantini R and Rozanski K 2005 Isotopes in lake studies: A historical perspective; In: Isotopes in the Water Cycle, Past, Present and Future of a Developing Science (eds) Aggarwal P K, Gat J R and Froehlich K F O, Springer, Vienna; The Netherlands, pp. 139150 .

Gat J R 1980 The isotopes of hydrogen and oxygen in precipitation; In: Handbook of Environmental Isotope Geochemistry 1. The Terrestrial Environment (eds) Fritz $\mathrm{P}$ and Fontes J C, Elsevier, Amsterdam, pp. 2147.

Gat J R 1996 Oxygen and hydrogen isotopes in the hydrologic cycle; Annu. Rev. Earth Planet Sci. 4 225-262, https://doi.org/10.1146/annurev.earth.24.1.225.

Gat J R, Klein B, Kushnir Y, Roether W, Wernli H, Yam $\mathrm{R}$ and Shemesh A 2003 Isotope composition of air moisture over the Mediterranean Sea: An index of the air-sea interaction pattern; Tellus B55(5) 953-965, https://doi. org/10.1034/j.1600-0889.2003.00081.x.

Gat J R, Ben-Mair R, Yam R, Yakir D and Wernli H 2005 The isotope composition of atmospheric waters in Israel's coastal plain; In: Isotopic Composition of Precipitation in the Mediterranean Basin in Relation to Air Circulation Patterns and Climate (ed.) IAEA, TECDOC-1453, Vienna, pp. 99-114.

Gatz D F and Smith L 1995 The standard error of a weighted mean concentration-II estimating confidence intervals; Atmos. Environ. 29 1195-1200.

Giorgi F 2002 Dependence of the surface climate interannual variability on spatial scale; Geophys. Res. Lett., https:// doi.org/10.1029/2002GL016175. 
Gonfiantini R, Roche M A, Olivry J C, Fontes J C and Zuppi G M 2001 The altitude effect on the isotopic composition of tropical rains; Chem. Geol. 181 147-167. https://doi. org/10.1016/S0009-2541(01)00279-0.

Harrington G A, Cook P G and Herczeg A L 2002 Spatial and temporal variability of ground water recharge in Central Australia: A tracer approach; Ground Water 40(5) 518528.

Hoefs J 2009 Stable Isotope Geochemistry; 6th edn, SpringerVerlag, Berlin.

Hurrell $\mathrm{J} \mathrm{W}$, Hoerling $\mathrm{M} \mathrm{P}$, Philliphs $\mathrm{A} \mathrm{S}$ and $\mathrm{Xu} \mathrm{T}$ 2004 Twentieth century North Atlantic climate change. Part I: Assessing determinism; Clim. Dyn. 23 371389.

IAEA (International Atomic Energy Agency) 1983 Palaeoclimates and palaeowaters: A collection of environmental isotope studies; Proceeding of an Advisory Group Meeting, IAEA, Vienna.

IAEA (International Atomic Energy Agency) 1995 Isotopes in water resources management; Proceeding of a Symposium 1-2, IAEA, Vienna.

IAEA (International Atomic Energy Agency) 1998 Application of isotope techniques to investigate groundwater pollution; IAEA-TECDOC-1046, Vienna.

IAEA (International Atomic Energy Agency) 2005a Isotopes in the water cycle; In: Past, Present and Future of a Developing Science (eds) Aggarwal P K, Gat J R and Froehlich K F O, Springer, Vienna, The Netherlands.

IAEA (International Atomic Energy Agency) 2005b Isotopic composition of precipitation in the Mediterranean basin in relation to air circulation patterns and climate; IAEATECDOC-1453, Vienna.

IAEA-WMO (International Atomic Energy Agency-World Meteorological Organization) 2006 Global network of isotopes in precipitation: The GNIP database; IAEA, Vienna, http://isohis.iaea.org.

Ingraham N L 1998 Isotopic variations in precipitation; In: Isotope Tracers in Catchment Hydrology (eds) Kendall C and McDonnell J J, Elsevier, Amsterdam, pp. 87-115.

Johnsen S J, Dansgaard W and White J W C 1989 The origin of Arctic precipitation under present and glacial conditions; Tellus 41B 452-468.

Kattan Z 1997a Environmental isotope study of the major karst springs in Damascus limestone aquifer systems: Case of the Figeh and Barada springs; J. Hydrol. 193 161182.

Kattan Z 1997b Chemical and environmental isotope study of precipitation in Syria; J. Arid Environ. 35 601-615.

Kattan Z 2006 Characterization of surface water and groundwater in the Damascus Ghotta basin: Hydrochemical and environmental isotopes approaches; Environ. Geol. 51(2) 173-201.

Koch P L 1998 Isotopic reconstruction of past continental environments; Ann. Rev. Earth Planet. Sci. 26 573-613.

Kumar U S, Kumar B, Rai S P and Sharma S 2010 Stable isotope ratios in precipitation and their relationship with meteorological conditions in the Kumaon Himalayas, India; J. Hydrol. 391 1-8.

Lee J E and Fung I 2008 'Amount effect' of water isotopes and quantitative analysis of post-condensation processes; Hydrol. Process. 22 1-8, https://doi.org/10.1002/hyp. 6637 .
Liotta M, Bellissimo S, Favara R and Valenza M 2008 Isotopic composition of single rain events in the central Mediterranean; J. Geophys. Res. 113 D16304.

Liu Z, Bowen G J and Welker J M 2010 Atmospheric circulation is reflected in precipitation isotope gradients over the conterminous United States; J. Geophys. Res. 115 D22120.

Lykoudis S P and Argiriou A A 2007 Gridded data set of the stable isotopic composition of precipitation over the eastern and central Mediterranean; J. Geophys. Res. 112 d18107.

Lykoudis S P, Argiriou A A and Dotsika E 2010 Spatially interpolated time series of $\delta^{18} \mathrm{O}$ in Eastern Mediterranean precipitation; Glob. Planet. Change 71 150-159.

Managave S R, Jani R A, Narayana Rao T, Sunilkumar K, Satheeshkumar S and Ramesh R 2016 Intra-event isotope and raindrop size data of tropical rain reveal effects concealed by event averaged data; Clim. Dyn. 47(3-4) 981-987.

Mathieu R and Bariac T 1996 An isotopic study $\left({ }^{2} \mathrm{H}\right.$ and ${ }^{18} \mathrm{O}$ ) on water movements in clayey soils under a semiarid climate; Water Resour. Res. 32 779-789.

Mook W M E 2001 Environmental isotopes in the hydrological cycle: Principles and applications; UNESCO/IAEA Series.

Nir A 1967 Development of isotope methods applied to groundwater hydrology; In: Proceeding of a Symposium on Isotope Techniques in the Hydrological Cycle; Am. Geophys. Union Monogr. Series No. 11.

Peng T R, Wang C H, Huang C C, Fei L Y, Chen C T A and Hwong J L 2010 Stable isotopic characteristic of Taiwan's precipitation: A case study of western pacific monsoon region; Earth Planet. Sci. Lett. 289 357-366, https://doi. org/10.1016/j.epsl.2009.11.024.

Prizgonov V, Nitashov V and Steriocovitch P V 1988 Determination of recharge zone of Damascus basin by the use of oxygen-18 in groundwater; Nawca (Russian ed.), Moscow.

Rozanski K, Araguas-Araguas L, Gonfiantini R 1993 Isotopic patterns in modern global precipitation; In: Climate Change in Continental Isotopic Records (eds) Swart P K et al. (Geophys. Monogr. Series, Vol. 78), AGU, Washington, DC, pp. 1-37.

Saad Z, Kazpard V, El Samrani A G and Slim K 2005 Isotopic composition of rainwater, Lebanon; J. Environ. Hydrol. 13(29) 1-11.

Scholl M A, Shanley J B, Zegarra J P and Coplen T B 2009 The stable isotope amount effect: New insights from NEXRAD echo tops, Luquillo mountains, Puerto Rico; Water Resour. Res. 45 w12407. https://doi.org/10.1029/ 2008WR007515.

Schotterer U, Oldfield F and Fröhlich K 1996 GNIP: Global network for isotopes in precipitation; Catalog, S.l.:s.n., http://lib.ugent.be/catalog/rug01:001441289.

Schulz H D and Zabel M 2006 Marine Geochemistry; 2nd edn, Springer-Verlag, Berlin, Heidelberg.

Smith R B 1992 Deuterium in north atlantic storm tops; J. Atmos. Sci. 49 2041-2057.

Sturm K, Hoffmann G, Langmann B and Stichler W 2005 Simulation of $\delta^{18} \mathrm{O}$ in precipitation by the regional circulation model REMOiso; Hydrol. Process. 19(17) 3425-3444, https://doi.org/10.1002/hyp.5979. 
Sturm C, Hoffmann G and Langmann B 2007 Simulation of the stable water isotopes in precipitation over South America: Comparing regional to global circulation models; J. Climate 20 3730-3750.

Tanhua T, Hainbucher D, Schroeder K, Cardin V, Alvarez M and Civitarese G 2013 The Mediterranean Sea system: A review and an introduction to the special issue; Ocean Sci. 9 789-803, https://doi.org/10.5194/os-9-789-2013.

Tanweer A 1993 Determination of deuterium in brines and in hypersaline aqueous solutions by mass spectrometry using zinc as reducing agent; Analyst 118 835-838, https://doi. org/10.1039/AN9931800835.
Windhorst D, Waltz T, Timbe E, Frede H G and Breuer L 2013 Impact of elevation and weather patterns on the isotopic composition of precipitation in a tropical mountain rainforest; Hydrol. Earth Syst. Sci. 17 409-419.

Yurtsever Y and Gat J R 1981 Atmospheric waters; In: Stable isotope hydrology, deuterium and oxygen-18 in the water cycle (eds) Gat J R and Gonfiantini R, Technical Report Series No. 210, IAEA, Vienna, pp. 103-142.

Zahn A, Barth V, Pfeilsticker K and Platt U 1998 Deuterium, oxygen-18, and tritium as tracers for water vapour transport in the lower stratosphere and tropopause region; J. Atmos. Chem. 30 25-47.

Corresponding editor: RAJNEESH BHUTANI 